\title{
INVESTOR SENTIMENT EFFECT IN STOCK MARKETS: STOCK \\ CHARACTERISTICS OR COUNTRY-SPECIFIC FACTORS?
}

\author{
P. Corredora \\ E. Ferrerb \\ R. Santamaria ${ }^{c}$ \\ a,b,c Department of Business Administration
}

Public University of Navarre

(Spain)

Corresponding author:

'Rafael Santamaria. Department of Business Administration. Public University of Navarre. Campus de Arrosadia s/n 31008 Pamplona (SPAIN). Ph. 34 948169389. Fax 3494169404 e-mail: rafael@unavarra.es

Coauthors:

aPilar Corredor. Department of Business Administration. Public University of Navarre. Campus de Arrosadia s/n 31008 Pamplona (SPAIN). Ph. 34 948169380. e-mail: corredorp@unavarra.es

bElena Ferrer. Department of Business Administration. Public University of Navarre. Campus de Arrosadia s/n 31008 Pamplona (SPAIN). Ph. 34 948169369. e-mail: elena.ferrer@unavarra.es

(C) 2013. This manuscript version is made available under the CC-BY-NC-ND 4.0 license http://creativecommons.org/licenses/by-nc-nd/4.0/ 


\title{
INVESTOR SENTIMENT EFFECT IN STOCK MARKETS: STOCK CHARACTERISTICS OR COUNTRY-SPECIFIC FACTORS?
}

\author{
ABSTRACT \\ This paper analyzes the investor sentiment effect in four key European stock markets: \\ France, Germany, Spain and the UK. The findings show that sentiment has a significant \\ influence on returns, varying in intensity across markets. The variation appears to involve \\ both stock characteristics and cross-country cultural or institutional differences. The \\ results also show sensitivity to the choice of sentiment proxy.
}

KEYWORDS: Sentiment, stock markets, stock characteristics, country-specific factors, European stock markets

JEL code : G10, G14

\section{INTRODUCTION}

Investor sentiment can be defined as investor opinion, usually influenced by emotion, about future cash flows and investment risk (Chang et al. 2012). Some researchers also explain it as the propensity to speculate or the optimism or pessimism about a given asset (Baker and Wurgler, 2006).

The suggested causes are diverse. Baker and Wurgler (2006) argue that the effect is not uniform across all stocks and is more likely to be associated with certain types of stock, particularly those that are hard to value or to arbitrage. Their results prove that when sentiment is high/low this type of stocks suffers from over/under pricing, which later reverts.

Schmeling (2009) offers arguments centered on country-specific factors, suggesting that the results depend decisively on the level of institutional quality and country-specific cultural factors. Chang et al. (2012) also focus on country-specific factors, attributing importance to differences in information quality, legal systems or corporate governance. These last works therefore appear to suggest that country-specific factors, such as the level of market integration and certain cultural factors hold the key to explaining the effect of investor sentiment on future stock returns.

In this context, this paper aims to analyze the role played by stock characteristics in explaining the effect of sentiment on future stock returns. The arguments put forward in the above-mentioned literature, however, suggest the need to analyze whether the 
sentiment effect depends on stock characteristics, country-specific factors, or a combination of the two. The results of individual analyses by country or by stock characteristics can be difficult to interpret. Let us consider a characteristic-based analysis (size, btm, volatility, dividends,...) and two countries, A and B. If the results indicate, for example, that the impact of market sentiment on size portfolio returns is stronger in country A than in B, there is no way to know whether this result is to be attributed to the stock characteristic (size) or to the country effect. Clearer conclusions to support one explanation or the other could be drawn by using controls for country effects or, alternatively, if the characteristic (size) has the same dispersion in both countries. Otherwise, either cause is possible. The commonest solution for determining which effect is responsible involves the analysis of portfolios that are neutral to one of the variables, say the country, or the use of techniques to isolate the effect. Results obtained using methods such as these enable assessment of the specific role of each variable, in this case the stock characteristic (size). If the results do not indicate impact of investor sentiment on portfolio returns but the analysis by individual countries reveals a significant country effect, the latter is obviously the sole cause. Significant returns obtained after controlling for the country effect will be entirely attributable to the stock characteristic. In the latter case, strategies that track cross-market dispersion in the characteristic in question will help to test for an additional effect relating to country-specific cultural or institutional factors.

This paper contributes in various ways to the financial literature. Firstly, it uses a set of tests, including country-neutral strategies and multilevel regression, in order to determine whether stock characteristics, country-specific factors, or a combination of the two can explain the intensity of the investor sentiment effect on future stock returns. As far as we are aware, this matter has not been addressed previously, since the literature has approached the problem by analyzing the two possible causes separately. Secondly, it performs separate analyses of four key European markets, France, Germany, Spain and the United Kingdom. Most previous studies on this subject have reported on sets of countries that are widely diverse in terms of financial development. Their findings may therefore be due to differences of this nature rather than to market-specific cultural and institutional factors. Our intention in considering four countries with similar levels of financial development is to enable us to eliminate any effects arising from disparities in this respect. Finally, another contribution of this paper is that it analyses the role of the overall US and European investor sentiment and includes a robustness test of the importance of the choice of the sentiment indicators in the construction of the investor sentiment proxy. We performed further analyses using direct measures of investor sentiment. The remainder of the paper proceeds as follows. Section 2 presents the literature review. Section 3 describes the database and the basic structure of the investor sentiment proxy. 
Section 4 presents a parametric discussion of the results for the individual markets. Section 5 analyses whether the investor sentiment effect depends on the stocks or country being analyzed. Section 6 contains a discussion of the various issues involved in the choice of proxies for investor sentiment, and comments on the influence on results. Finally, section 7 outlines the main conclusions of the study.

\section{LITERATURE REVIEW}

According to classic finance theory, prices in equilibrium only reflect the discounted value of expected cash flows. Thus, any possible variations will depend only on systematic risk. Within this context, investor sentiment does not constitute a relevant factor, since the presence of irrational investors trading on sentiment is soon offset by the remainder of rational investors in the market trying to bring prices into equilibrium.

The behavioral finance literature suggests that sentiment affects trading decisions. The influence of investors' future expectations can bring about the over- or under- pricing of stocks, and thus affect pricing models.

Early empirical evidence centered on demonstrating how sentiment predicts future returns in the US stock market (Kothari and Shanken, 1997; Neal and Wheatley, 1998; Shiller, 1981, 2000; Baker and Wurgler, 2000; and Brown and Cliff, 2005) and estimating the effect of sentiment on small-stock premiums (Lee et al., 1991; Swaminathan, 1996; Neal and Wheatley, 1998; Brown and Cliff, 2004; and Lemmon and Portniaguina, 2006). Zhu (2012) models time-varying return distribution through quantile regressions and copulas and uses sentiment index as a potential candidate to predict the return distribution.

Another set of studies examine the possibility of a causal relationship between index returns and changes in investor sentiment, failing to find any sentiment effect on short-run returns (Otoo, 1999; Jansen and Nahuis, 2003; Brown and Cliff, 2004; and Wang et al., 2006).

Focusing on other financial markets, Wang $(2001,2003)$ analyze the sentiment effect in the futures market, Han (2008), and Lemmon and Ni (2011) in the options market, Ahn et al. (2002) in the currency market and Burghardt et al. (2008) and Schmitz et al. (2009) in the warrants market.

The two main channels through which sentiment can affect pricing are investor sentiment and arbitrage. Under the first of these channels, sentimental demand shocks vary across stocks while arbitrage limits are constant. Interpreting sentiment as the propensity to speculate, sentiment increases the relative demand for stocks that are vulnerable to speculation, whose valuations are subjective and difficult to determine, and whose contemporaneous returns are higher than is justifiable. Specifically, small stocks, high volatility stocks, extreme growth stocks, distressed stocks, young stocks and non dividend- 
paying stocks, should be the most difficult to price and, therefore, the most vulnerable to investor sentiment.

Under the second, interpreting sentiment as optimism or pessimism about stocks in general, the effect of changes in sentiment will be uniform but the difficulty of arbitrage differs among stocks. In fact, the literature has shown that arbitrage is particularly costly and risky with certain stock types (young stocks, small stocks, unprofitable stocks, extreme growth stocks or distressed stocks).

These two channels appear to affect the same type of stocks, or, put another way, the most speculative stocks are also the hardest to arbitrage and this profile of characteristics will therefore be the most influenced by investor sentiment. Lemmon and Portniaguina (2006) find this effect to be present particularly in small stocks and with less institutional ownership. Baker and Wurgler (2006, 2007) find that small stocks, young stocks, high volatility stocks, unprofitable stocks, non-dividend-paying stocks, extreme growth stocks and distressed stocks are the most heavily affected by periods of pessimism, and likely to suffer from over- or under-pricing, depending on investor sentiment.

Chiou, et al. (2010) find that legal environment influences performance and risk premiums. Chui et al. (2010), for their part, argue that cultural differences between countries may be an element of behavioral bias. In fact, the herding tendency among uninformed investors or collectivism may intensify the relationship between stock returns and investor sentiment with changes in sentiment. Pursuing this issue, a number of studies that have analyzed a range of international markets have reported findings pointing towards differences between the countries analyzed. Schmeling (2009) shows that sentiment has an effect on return in 9 of the 18 countries analyzed. His results, which point towards country-specific characteristics, appear to suggest a stronger effect in countries marked by herd-like trading behavior, investor overreaction and lower market integrity (institutional development and information quality). Chang et al. (2012) show that the sentiment effect has more impact in developed than developing countries. The earlier of these two papers highlights the greater intensity of the effect in countries characterized by a higher level of collectivism and greater access to information media, in partial contradiction to Schmeling (2009). The latter suggests that higher quality in the legal and corporate governance environments intensifies the sentiment effect. The fact that both these studies analyze countries with widely differing levels of financial development means that their findings may be masking a situation of this nature.

Baker et al. (2012) analyzes several aspects of (global and local) sentiment, observing their impact on stock returns. They also explore the effects on other countries' stock markets, given that the effect of the US investor sentiment is contagious across markets. Gutierrez et al. (2009) show that Asian ETF returns are highly correlated with U.S. markets, indicative of the effects of investor sentiment and location of trade. 
The empirical evidence reveals two complementary strands of research. One set of studies investigates the effect of investor sentiment on the returns of the most sentiment-sensitive stock (Baker and Wurgler, 2006 and 2007; Baker et al., 2012). The other analyses the effect of sentiment on stock returns in various countries, focusing on cross-country structural differences as the key source of variation in the intensity of the effect (Schmeling, 2009; Chang et al., 2012). As mentioned in the introduction, separate analysis of either of these effects can lead to misleading findings. This study aims to obtain clearer findings by interlinking both ideas and using techniques allowing the isolation of the country effect in characteristic-based analysis.

Another key issue is the actual measurement of the sentiment variable. This varies from one study to another, with researchers drawing on numerous indicators including investor survey findings (Otoo, 1999; Jansen and Nahuis, 2003; Brown and Cliff, 2005; Lemmon and Portniaguina, 2006; Qiu and Welch, 2006 and Schmeling, 2009), investor mood (Kamstra et al., 2003), retail investor trades (Barber et al., 2006; Greenwood and Nagel, 2006 and Kumar and Lee, 2006), mutual fund flows (Brown et al., 2003; Frazzini and Lamont, 2008), the dividend premium (Baker and Wurgler, 2004a and b), the closed-end fund discount (Zweig, 1973; Lee et al., 1991; Swaminathan, 1996; Neal and Wheatley, 1998 and Doukas and Milonas, 2004), option implied volatility (Whaley, 2000), the number of IPOs and average first-day IPO returns (Ljungqvist et al., 2006), turnover or trading volume (Jones, 2002; Sheinkman and Xiong, 2003 and Baker and Stein, 2004), the share of equity issues in total equity and debt issues (Baker and Wurgler, 2000), insider trading (Seyhun, 1998) or composite sentiment indexes (Brown and Cliff, 2004; Baker and Wurgler, 2006, 2007; Ho and Hung, 2009; Baker et al., 2012, and Chang et al., 2012;) among others.

The theory does not seem to have developed any clear criteria for assessing the validity of one variable in relation to others or even for the breakdown of a variable into its constituent parts (Baker et al., 2012 or Chang et al., 2012;). This study aims to explore this issue by analyzing the robustness of the results to different composite measures and observing the effect of including or excluding certain variables in the construction of the different sentiment proxies. As a robustness test we also employ direct sentiment measures.

\section{DATABASE: STOCK CHARACTERISTICS AND SENTIMENT}

\subsection{Stock characteristics}

The data, taken from the Datastream database (Thomson Financial), refer to all stock currently or formerly listed in four of the key European markets: France (FR), Germany (GR), Spain (SP) and the United Kingdom (UK), thus avoiding survivorship bias. In line with Ince and Porter (2006), we have screened and corrected the database. We have removed padded zero-return records at the end of delisted firms, we have removed all 
nonlocal firms and all listing other than those on the primary exchange and all listing with Type not equal to Equity. We include only those firms that checked YES in the "Primary quote" field. Extremely high monthly returns were removed so that the portfolio monthly returns are no higher than $+-10 \%$.

The study is conducted in developed European markets in order to allow homogeneous comparisons between stocks and thus control as much as possible for the potential influence of the development level of the stock market in such comparisons. Although by limiting the analysis to only four countries we might risk underestimating the role of country-specific factors, our research objective demands homogeneity of financial development. The European markets featured in our study (the UK, France and Germany) are considered, along with the US and Japan, as extremely prominent economies on the global stage (Chang et al., 2012). Spain is also featured because, according to the World Stock Exchange Federation's latest data (2009 and 2010), the Spanish stock market group ranks as the fourth largest Exchange in Europe by market capitalization after the London SE Group, the NYSE Euronext (Europe) and the Deutsche Börse.

The homogeneity of the four selected countries in terms of financial development levels does not rule out important cultural and institutional differences, however. This combination of similarity and diversity strengthens the relevance of our findings by allowing us to determine whether country-specific cultural or institutional factors, unrelated to levels of financial development, play a significant role in the impact of investor sentiment on stock returns. Indeed, despite their similarity in terms of development levels, the four countries in question differ in dimensions of culture and corporate governance and in the quality of the legal environment. They also include countries representatives of both the Anglo Saxon and the Continental financial systems.

Regarding the first of these issues, according to measures developed by Hofstede (2001), we observe divergence in herd and overreaction behavior. The UK is a country with a high degree of individualism, displaying greater tolerance for uncertainty and ambiguity, while France and Spain score higher than the European average for their propensity to act in groups and in the uncertainty avoidance. The selected countries also have different shareholder and corporate governance structures. La Porta et al. (1998) also finds crosscountry differences in relation to shareholder and creditor protection, showing that it is stronger in countries governed by common law (such as the UK) and weaker in those governed by civil law, such as France and Spain. In addition, firm ownership concentration is greater and stock turnover is lower in Continental markets than in Anglo-Saxon markets, where there is a higher level of institutional ownership. Finally, in terms of the quality of the legal environment, on average, Spanish market agents are less inclined to adhere to social norms and have less confidence in the legal system than the average European investor. In the UK, in contrast, people have greater confidence in their country's legal system and corruption control mechanisms. 
The sample period runs from January 1990 to December 2007. The stock characteristics considered are the book-to-market ratio (BTM), size (SIZ) measured as the stock market capitalization of each firm in thousands of Euros, volatility (VOL) measured as the last twelve months' standard deviation, and the dividend per share ratio (DIV). The descriptive statistics of the stock characteristics of each country, shown in Table 1, include the data for the overall period and for two sub-periods in order to illustrate changes in the variables through time.

The analysis requires the construction of long-short portfolios based on each of the abovementioned stock characteristics, using different time horizons. The short-term analysis requires monthly stock returns, whereas the long-term analysis requires cumulative returns for several periods. To address problems arising from autocorrelation and overlapping observations in the calculation of the latter, this study follows the proposal given in Chang et al. (2012) which is to adopt the calendar-time approach used by Jegadeesh and Titman (2001) to study the momentum effect. Thus, each month, we sort the stocks by the corresponding characteristic $j$ and group the returns into quintiles. We then compute the average returns in each of the following $\mathrm{t}+\mathrm{k}$ months, where $\mathrm{k}$ denotes the selected time horizon. From the resulting data, we compute the differences between the extreme portfolios in every month of the horizon $\mathrm{k}$. These are denoted as the differential portfolios. Finally, the return of the portfolio assigned to a given month is calculated from the average of the $\mathrm{k}$ returns of that month's differential portfolios according to the classifications for each of the preceding $\mathrm{k}$ months ${ }^{1}$.

Thus, over/underpricing due to high/low investor sentiment will be greatest in the quintiles that are hardest to arbitrage or value (the first size and dividend quintiles and the fifth volatility quintile). Presumably, therefore, the current returns in these portfolios will be higher/lower than at the opposite end of the quintile distribution. The sentiment effect on the BTM ratio may be the result of two dimensions potentially interacting with it, one being high growth stocks (first quintile), the other, the most distressed stocks (fifth quintile)2 ${ }^{2}$. To avoid this multidimensional effect, high-medium (H-M) and medium-low (ML) portfolios were also constructed.

\footnotetext{
1 The differential portfolio is the difference in returns between the top and bottom $20 \%$ of the stock classification. Baker and Wurgler (2006), Baker et al. (2012), Chang et al. (2012) use the top and bottom 30\%. The use of a smaller percentage in this paper enables the classification of more extreme, and thus clearly differentiated, stocks which can be expected to show a stronger sentiment effect. When the analysis was repeated using the top and bottom $30 \%$, the sentiment effect on the stocks in question was, as predicted, less intense than for the top and bottom $20 \%$.

2 The studies reported in Baker and Wurgler (2006) and Chang et al. (2012) include another series of stock characteristics representing profitablity or tangibility and variables such as age, sales growth, R\&D investment or external finance. These variables could not be included in this study because the necessary data were not available for the markets under analysis.
} 


\subsection{Investor Sentiment}

The literature has used several different measures of investor sentiment, as described in the theoretical framework. Baker and Wurgler (2006) use principal components analysis to construct an index aggregating a series of sentiment indicator variables: the closed-end fund discount, stock turnover, number of IPOs and average IPO first-day returns, the equity share in new issues and the dividend premium. This index (to be referred to henceforth as the BW index) has been used in several recent studies including Baker and Wurgler (2006, 2007), Baker et al. (2012), Chang et al. (2012), where it is accepted as an appropriate measure of sentiment. It is one of measures used to analyze the sentiment effect in this study. Details of the BW index are available on Wurgler's web site ${ }^{3}$. Given that countries that concern us are European and the BW index was constructed for the US market, this study also includes a composite index for all four of the countries of interest, France (SENT FR), Germany (SENT GE), Spain (SENT SP) and the UK (SENT UK), as suggested in Baker et al. (2009). As far as possible with the available data for these countries, the variables representing the country-specific factors are ${ }^{4}$ : turnover, the volatility premium and the consumer confidence index. Turnover (TURN) is measured as the natural log of the raw turnover ratio, detrended by the five- year moving average. The volatility premium (VP) is calculated by taking the log of the average BTM ratio of high volatility stocks (the top $30 \%$ ) and low volatility stocks (the bottom $30 \%$ ). Finally, the consumer confidence index (CC) is published by the European Commission every working day of each month for each member state ${ }^{5}$. The first two variables are the same as those used in the BW index; the aim of the third is to compensate the lack of IPO data ${ }^{6}$.

The reason for the consideration of these variables is their relationship with the level of investor sentiment. In fact, Baker and Stein (2004) consider turnover as a sentiment indicator because in a market with short-selling constraints, high liquidity is a symptom of the fact that the market is dominated by a class of irrational investors, who underreact to the information contained in the order flow, and hence is overvalued. High turnover is also a sign of positive investor sentiment, and thus relatively low expected returns. Jones (2002)

\footnotetext{
${ }^{3} \mathrm{http}: / /$ www.stern.nyu.edu/ jwurgler

${ }^{4}$ The availability of data determines the sample period for the analysis including SENT EU as July 1992 to December 2007.

5 The consumer confidence index data were obtained from the European Commission web site: http://ec.europa.eu/economy_finance/db_indicators/surveys/index_en.htm

${ }^{6}$ The last section of the paper describes a robustness test on the construction of the sentiment index. Some of the data required (number of IPOs and IPO first day returns for Spain and number of IPOs for the UK) for this test was not available for all of the markets considered.
} 
also shows an association between liquidity shifts and low future returns in the aggregate market.

Baker et al. (2012) used the volatility premium, which is a proxy for relative investor demand between high and low periods of volatility. Conceptually, it is similar to that of the dividend premium, which is a proxy for relative investor demand between dividend-paying and non-paying stocks. These two variables are negatively correlated. High volatility stocks tend to be small stocks with low growth potential and dividend non-paying stocks, the demand for which increases with investor sentiment. For a set of countries including three of the four markets analyzed in this study, together with Canada and Japan, Baker et al. (2009) use the volatility premium to replace the dividend premium, which is inappropriate in countries where dividends are uncommon ${ }^{7}$. Finally, the consumer confidence index captures household spending and savings data and investors' perceptions of the economic factors involved. The main advantage of this measure is that extended sets of data are available for practically all countries, enabling cross-country comparison. Another positive feature is its independence of market trading.

From the three above variables, we derive a sentiment index for each country using the same mechanism as Baker and Wurgler (2006). We start by estimating the first principal components of three proxies and their lags. This gives a first-stage index with six loadings and the variable is included in $\mathrm{t}$ or $\mathrm{t}-1$, depending on which is most highly correlated with the first stage-index ${ }^{8}$. The first principal component for France explains 52.677\% of the total variance, that of Germany 53.045\%, that of Spain $70.111 \%$ and that of the UK $39.467 \%$ of the variance explained, enabling the conclusion that the first factors explain a high proportion of the common variance between the three measures. The sentiment index coefficients for each country are as follows:

$$
\begin{aligned}
& \text { SENT FR }_{\mathrm{t}}=0.487 \mathrm{CC}_{\mathrm{t}}-0.355 \text { TURN }_{\mathrm{t}-1}+0.519 \mathrm{VP}_{\mathrm{t}-1} \\
& \text { SENT GE }_{\mathrm{t}}=0.484 \mathrm{CC}_{\mathrm{t}}+0.557 \text { TURN }_{\mathrm{t}-1}+0.290 \mathrm{VP}_{\mathrm{t}-1} \\
& \text { SENT SP }_{\mathrm{t}}=0.424 \mathrm{CC}_{\mathrm{t}-1}-0.386 \mathrm{TURN}_{\mathrm{t}}+0.382 \mathrm{VP}_{\mathrm{t}-1} \\
& \text { SENT UK }_{\mathrm{t}}=0.602 \mathrm{CC}_{\mathrm{t}}+0.575 \mathrm{TURN}_{\mathrm{t}-1}+0.390 \mathrm{VP}_{\mathrm{t}-1}
\end{aligned}
$$

The descriptive statistics of the sentiment indicators of each country are summarized in Table 2 together with their correlations with the three sentiment proxies used to construct them. The results show that consumer confidence has a positive influence on the four sentiment indicators, as does the volatility premium. The most unevenly distributed

\footnotetext{
7 To enable comparison with the results of their 2009 study, the authors use the volatility premium to replace the dividend premium used in their 2006 study.

8 The correlation between the 6-term first-stage index and their corresponding indexes is 0.935 for France, 0.965 for Germany, 0.961 for Spain and 0.820 for the United Kingdom. This suggests that little information is lost by dropping the three terms with other subscripts.
} 
variable is turnover, which shows positive correlation for the UK and Germany and negative for France and Spain ${ }^{9}$.

Since the analysis also requires an overall European sentiment indicator, the same principal component analysis approach is used to create a new aggregate index for all four countries, denoted by SENT EU10. The index scores by country are:

$\operatorname{SENT~EU}_{\mathrm{t}}=0.270 \mathrm{SENT} \mathrm{UK}_{\mathrm{t}}+0.367 \mathrm{SENT} \mathrm{GE}_{\mathrm{t}}+0.387 \mathrm{SENT} \mathrm{FR}_{\mathrm{t}}+0.410 \operatorname{SENT~SP}_{\mathrm{t}}(5)$

All four countries show significant positive correlation. Table 3 shows the correlations between the country-specific indexes and the aggregate index and between the countryspecific indexes and the BW index. All the European sentiment indicators used in the analysis show positive and significant relationships except the coefficient of correlation between the UK and Germany, where the relationship lacks significance. The BW index shows significant positive correlation with the European sentiment index and with all the country-specific sentiment indexes, the lowest correlation is with SENT UK.

Figure 1 is a graph of investor sentiment over the sample period. The overall trend is an increase in the sentiment effect until 2001, declining afterwards until 2003. It is worth noting the UK results for the final period, which include the greatest fluctuations in investor sentiment.

\section{RESULTS ANALYSIS: RETURN FORECASTS}

\section{1- Feedback effects between investor sentiment and near-term stock returns}

Previous analyses of the short-term effects of investor sentiment on stock returns include Solt and Statman, 1998; Otoo, 1999; Fisher and Statman, 2000; Brown and Cliff, 2004 and Schmeling, 2009, among others. The conclusions drawn from their findings indicate the possibility of short-term feedback effects due to the contemporaneous relationship between sentiment measures and returns.

To test this time series dependency, we use the VAR technique, which is a useful tool for detecting this type of short-term relationship. Brown and Cliff (2004) and Schmeling (2009) apply it for the same purpose using one-period lagged returns, and then use regressions for the long-run analysis. Brown and Cliff (2004) obtain that, while sentiment is driven by past returns to both large and small firms, it is only the stock returns of small firms that are driven by sentiment, not those of large ones. In Schmeling (2009), which uses a pool of

\footnotetext{
${ }^{9}$ The exception is turnover in France and Spain, which is not positively correlated with the rest of the components used to construct these indices. For France, it has a correlation of -0.16 with CC and -0.25 with PV. The correlations for Spain are -0.62 with CC and -0.43 with PV. Baker et al. (2012) also find contrary to the expected sign of correlation with PV for France, attributing it to the negative correlations observed with the rest of the measures used to construct their composite indicator for France.

10 This index captures $47.654 \%$ of the variance explained.
} 
countries, the Granger's test results reveal the presence of feedback between sentiment and short-run returns.

The Granger's test results obtained from the VAR analysis of our four markets are given in Table 4. To analyze the relationship, we use a set of self-financed stock portfolios, each exposed to one of the four characteristics: size (small-large), volatility (high-low), book-tomarket (high-low) and dividends (hig-low). The returns used for each portfolio are the average one-month lagged returns of the set of stocks used to construct the portfolio. Following Baker and Wurgler (2006) and Schmeling (2009), we include, as exogenous variables, four macroeconomic variables $\left(\mathrm{M}_{\mathrm{s}}\right)$ (industrial output index, durable goods consumption, consumer goods consumption, and the unemployment index) to protect the results from the effect of possible changes in the economic cycle.

The results are not homogeneous across all markets or for all choices of sentiment proxy. Observing the data when the BW sentiment indicator is being used, we find that the causality tends to run from sentiment to returns. This shows itself even more clearly when we come to analyze the BTM and size portfolios for the UK, the volatility portfolio for France, Germany and the UK and the dividend portfolio for Germany, Spain and the UK. One notable exception is the BTM portfolio for France, which shows past returns driving current sentiment in the BTM portfolio. When we analyze the interaction with EU sentiment, the relationship emerges clearly in the volatility portfolios (SP, FR and UK) and the dividend portfolios (SP and UK) showing that returns drive sentiment. Analysis of the BTM portfolio for FR shows sentiment driving returns. Finally, the size portfolio for the UK shows a feedback effect ${ }^{11}$.

This somewhat confusing array of results, which differs little from the findings reported in other studies, is due to the nature of the two implied variables, and the fact that this is a short-run analysis. This span of analysis highlights the difficulty of demonstrating the ability of sentiment to predict subsequent short-run returns. As argued by Brown and Cliff (2005), short-term predictability would lead to simple trading strategies that would generate abnormal returns. However, the lack of short-term predictability does not mean that sentiment has no impact on longer-run returns.

The focus of our study is on the long-run relationship between the level of investor sentiment and stock returns, because mispricing can be a long-run phenomenon (Brown and Cliff (2005)). As the cited authors argue, it is reasonable to view sentiment as a timepersistent variable. Furthermore, arbitraging forces can neutralize profitable short-term

\footnotetext{
11 In order to observe the degree of persistence in the return-sentiment relationship, we performed a complementary analysis of the impulse-response function, the results of which suggest that the relationship fades over time (2 to 3 months). Note that the returns used for this analysis are those immediately following the sentiment analysis period. A long-run analysis would require recalculation of the returns based on several months' accumulated data.
} 
trading strategies but not longer-run mispricing. Sentiment may therefore play an important role over a longer time horizon.

\section{2- Long-run effects between investor sentiment and stock returns.}

We test the predictive capacity of sentiment on the stock portfolios discussed earlier.

Additionally, since the potential growth and distressed stock portfolios tend to be classified into opposing quintiles, which are presumably the two most affected by sentiment, we construct three portfolios in order to detect possible differences between the extremes: highmedium for distressed stocks and medium-low for potentially high growth stocks.

As already stated, to avoid employing overlapping observations and overcome potential selfcorrelation problems arising from the construction of event-time portfolios over multiperiod we have used calendar-time portfolios for the different time horizons using the average monthly return over the previous $\mathrm{k}$ months of the $\mathrm{k}$ differential portfolios estimated for that month, in line with the procedure described in Jegadeesh and Titman (2001).

The correlation between the resulting portfolios is summarized in Table $5^{12}$. The smalllarge size portfolio shows significant positive correlation with the volatility portfolio and significant negative correlation with the dividend portfolio. The volatility portfolio also has significant negative correlation with the dividend portfolio. These results hold for all four of the markets considered. The two extreme BTM portfolios show significant negative correlation for Spain, but positive correlation for France, Germany and the UK.

Taking the four country portfolios (i= FR, GE, SP and UK) based on the above-mentioned characteristics (j=BTM, SIZ, VOL and DIV) and the three time horizons ( $\mathrm{k}=6,12$ and 24 months), the system of equations to be estimated for each characteristic $\mathrm{j}$ and time period $\mathrm{k}$ takes the following form:

$$
R_{h i g h, t+k}^{i, j}-R_{l o w, t+k}^{i, j}=\alpha_{k}^{i, j}+\beta_{k}^{i, j} \operatorname{Sent}_{t}+\sum_{s=1}^{4} \gamma_{k, l}^{i, j} M_{s, t}+u_{k, t}^{i, j} ; \mathrm{i}=1,4
$$

where $R_{h i g h, t+k}^{i, j}-R_{l o w, t+k}^{i, j}$ is the return to the self-financed portfolio for country i and characteristic j, over the holding period $\mathrm{k}$. Sentiment (Sent), measured alternately by the BW index and the European Union (SENT EU), are the independent variables. We also include the four macroeconomic variables described before.

To avoid the problems reported by Stambaugh (1999), caused by highly persistent regressors, we use a block bootstrap method ${ }^{13}$, as suggested by Schmeling (2009) and

\footnotetext{
12 The data are for the 12-month portfolios. The correlations between the 6- and 24-month portfolios (not shown) are similar. They are available from the authors upon request.

${ }^{13}$ We use block length $(l=6)$, by the criterion $\mathrm{l}=\mathrm{T}^{1 / 3}$ based on $\mathrm{l}=\mathrm{T}^{1 / 3}$, where $\mathrm{T}$ is the sample size. The results using l=12 are qualitatively similar. We resample the blocks and generate the bootstrap sample. We adopt the non-
} 
Goncalves and White (2005). Our bootstrap method is different from theirs, however, because we construct the long-short portfolios following the procedure described by Jegadeesh and Titman (2001), to avoid problems arising from overlapping observations. Under the hypothesis that investor behavior has no effect on stock prices, the sentiment effect should not be significant. The alternative hypothesis says that over/underpricing due to high/low investor sentiment drives current prices above/below equilibrium and therefore, that returns will be lower/higher in the future when prices revert to equilibrium. Thus, we expect a positive $\beta$ for the medium-low BTM portfolios reflecting potential growth and for the high-low dividend portfolio, and a negative $\beta$ for the distressed stock portfolio (highmedium BTM ratio), the small-big size portfolio and the high-low volatility portfolio. Table 6 gives the results of the estimation for the two indices analyzed. Overall, the results based on the BW index are in line with expectations, except the size portfolios, where the only significant coefficient is for the UK. More specifically, the coefficient for the high-low BTM portfolio is positive and significant for France, Germany, Spain ${ }^{14}$ and the UK. A similar sentiment effect appears in the volatility and dividend portfolios, with the expected signs: negative for volatility and positive for dividends. The coefficient for the medium-low BTM portfolio is positive and significant in France and the UK. Finally, the sentiment effect in the high-medium BTM portfolio does not have the expected sign in all four countries.

The results are less significant when the BW index is replaced with the EU index, however. While the same results hold with respect to size for the UK, the statistical significance of the sentiment effect in both the high-low and medium-low BTM portfolios is lost for the UK and France. The statistical significance of the sentiment effect on volatility and the dividend portfolios observed in all four markets when using the BW index, disappears in all except the UK ${ }^{15}$. This shows that, overall, the SENT EU proxy captures much less investor sentiment than the BW proxy does ${ }^{16}$.

overlapping method and resample the dependent and independent variables. We then calculate the OLS estimator. Finally we repeat this procedure 10,000 times and calculate the bootstrap p-values for the null hypothesis. We also estimate the model using the SUR (Seemingly Unrelated Regressions) method in order to deal with the high level of contemporaneous correlation between the individual regression errors, possibly resulting from the presence of common structural factors, or unknown variables affecting the dependent variable. The actual average residual correlation coefficient between Spain and the UK and between Spain and Germany obtained via the SUR methodology for the BW and SENT EU indices is 0.33. The mean correlation coefficients are 0.39 between Spain and France, 0.49 between the UK and Germany, 0.64 between the UK and France and 0.52 between Germany and France. The SUR results are very similar to those obtained with the block bootstrap procedure.

14 The exception is the 6-month portfolios, which do not present a significant sentiment effect in Germany and Spain.

${ }^{15}$ Its significance also holds for the 12 and 24-month portfolio for Germany and for the volatility portfolio.

16 In addition, Baker and Wurgler (2006) use different means to isolate the sentiment effect from changes in the macroeconomic variables, which is to construct the index to be orthogonal to these variables. The analyses were 
Given that the above results could be due to significant exposure of the portfolios to classic risk factors, a re-estimation was performed including variables to capture the Fama-French risk factors (Fama and French, 1993), resulting in an equation of the following form ${ }^{17}$ :

$$
R_{\text {high,t+k}}^{i, j}-R_{\text {low }, t+k}^{i, j}=\alpha_{k}^{i, j}+\beta_{k}^{i, j} \operatorname{Sent}_{t}+\sum_{s=1}^{4} \gamma_{k, l}^{i, j} M_{s, t}+\delta_{k}^{i, j} R M R F_{t}+\varphi_{k}^{i, j} S M B_{t}+\lambda_{k}^{i, j} H M L_{t}+u_{k, t}^{i, j}
$$

The results for both indices are given in Table 7. The BW index coefficients can be seen to have remained practically unaltered. The portfolios that were previously significant retain their significance, except the volatility portfolios for Spain. Previously unobserved significance emerges for the high-medium BTM portfolio for Germany. When the European index is applied, the results also fall in line with those obtained without the Fama-French factors, except for the effect on the dividend portfolio for the UK, where the incorporation of the factors causes the effect to lose significance. The results are largely identical, both with and without the factors being included, which means that the previous results cannot be due to the exposure of the portfolios to the classic risk factors.

In short, while interesting, the results obtained from the separate analysis of the four key European markets are less conclusive than analysis of the US market suggests. They also differ considerably across the countries considered. This appears to suggest country-specific effects reducing the explanatory capacity of stock characteristics, contrary to indications in Baker and Wurgler (2006). This may be a somewhat hasty conclusion, however, given the number of other factors influencing the results, including both potential cross-country differences in stock characteristics and country-specific variables, in line with the findings made by Chang et al. (2012), and the details of the sentiment index construction in each case.

\section{STOCK CHARACTERISTICS OR COUNTRY-SPECIFIC FACTORS}

The above results reveal considerable cross-country disparities, suggesting the possible influence of structural or cultural factors on the intensity of the sentiment effect in different countries. In fact, Schmeling (2009) and Chang et al. (2012) have investigated this as the possible cause of observed cross-country divergence, the case being strengthened by any evident lack of appreciable cross-country variation in stock characteristics.

repeated using the orthogonal US index proposed by BW and the orthogonalized European index. Overall, the results are similar, particularly for the BW index. Finally, to check the sensitivity of the results to the incorporation of the macroeconomic variables, the analysis is repeated without including them as independent variables. The results suggest that, when the BW index is used, the effect of sentiment on returns remains the same as when the macroeconomic variables were included, except for the size variable in the UK. If the European sentiment indicador is used, some previously unobserved relationships emerge, especially in the high-low and medium-low BTM porfolios.

17 The Fama-French HML factor is not included in the regressions of the BTM portfolios and the SMB factor is omitted from the regressions of the SIZE portfolio. 
Nevertheless, the observed findings would also be consistent with a key role for the country effect, where stock characteristics serve as the moderator variables.

In an attempt to settle this issue, we undertake two complementary procedures. The first is to pool the stocks of all four markets and observe the joint result. Obviously, if stock characteristics are relevant, it is in this context that the strongest sentiment effects should emerge, since, by using a larger number of stocks from samples that are not necessarily uniform, we also increase the dispersion in stock characteristics. If country-specific factors are the only relevant factor, the joint result would be smaller sentiment effect as a consequence of the mixed cultural or institutional aspects in one sample. In order to eliminate the country effect, the second procedure is to construct country-neutral strategies. By controlling for the country factor, it is possible to attribute whatever findings emerge directly to stock characteristics.

The results from the overall analysis of the pooled data for all four of the markets considered appear in Table 8 panel $\mathrm{A}^{18}$. These results show that the capacity of the sentiment effect to predict returns to the portfolios based on the above-mentioned stock characteristics is clearly significant, since even the lowest levels are on a par with the countries with the highest sentiment estimates ${ }^{19}$.

These findings appear to attribute an important role to stock characteristics, but for a more conclusive judgement, we must first turn our attention to the results for the countryneutral portfolios. We can use two alternative strategies to obtain these portfolios. The first assigns the same number of securities to all countries, thus giving them all equal weight. The other assigns to each country a number proportional to its share in the overall sample of securities. In the case in hand, this means that the average weight of each country in the country-neutral portfolio will be approximately France 23\%; Germany 20\%; Spain 4\%; and the UK $53 \%$.

The results shown in Table 8 for the equally-weighted portfolios (panel B) and the proportionally-weighted portfolios (panel C) reconfirm the above observations. Stock characteristics are relevant because, if the country variable were crucial, the global country-neutral portfolio returns should not be significant. The two country-neutral strategies produce similar results. The impact of investor sentiment is possibly slightly greater for the proportionally-weighted portfolios, which are dominated by the UK, the country with the highest sentiment effect estimates.

\footnotetext{
${ }^{18}$ Given that the inclusion of the risk factors had a negligible effect on the results, they are ommitted from the pooled data analysis. Furthermore, since it is more complicated to consider national macroeconomic variables in the overall analysis, the sentiment factor is orthogonalized as in Baker and Wurgler (2006). Finally, since the results are similar across the three holding periods considered, henceforth, for the sake of simplicity, all results presented are for the 12 month period.
}

${ }^{19}$ Except the size portfolio, where the only significant coefficient is for the UK. 
An alternative parametric way to construct country-neutral portfolios is to use multilevel regression, which enables the isolation of the effect of one variable, in this case, the country, from the subgroup to which it belongs. The results are shown in Table 9. As can be appreciated, the results using the BW index are very similar to those obtained using country-neutral portfolios.

When we use the SENT EU index results are clearer because the BTM (H-L) and BTM (ML) portfolios show statistically significant returns. In the case of the volatility portfolio, the level of significance is quite close to accepted levels $(\mathrm{p}=0.13)$.

The above findings clearly indicate that, once the country has been isolated, stock characteristics play an important role in explaining the impact of investor sentiment. Given the important differences observed in the country-by-country analysis, the next step is an analysis to determine whether country-specific cultural and institutional factors also play a role in the impact of investor sentiment. Note that the observed between-country variation may be due entirely to differences in the level of dispersion in stock characteristics and thus be unrelated to country-specific cultural or institutional factors, which is precisely what we aim to determine.

It is reasonable to suppose that if the country effect plays no role, the greater the dispersion in stock characteristics, the greater the impact we should observe of investor sentiment on stock returns. Therefore, the countries with the highest coefficients of variation in stock characteristics should also show the highest sentiment effect, while markets with less dispersion in this respect will be the least affected.

Table 10 displays the means of the time series of coefficients of variation in terms of the four characteristics considered for the markets under analysis. Here it emerges that Spain has the lowest coefficients of variation in all four characteristics, and therefore should supposedly be the least affected by investor sentiment. The highest coefficients correspond to Germany in the BTM ratio; the UK in size; and France in both volatility and dividends. Furthermore, the coefficients of variation for all four countries and all four stock characteristics are significantly different from $1 \%$, except those for size in the case of Germany and France and for volatility in that of Spain and Germany ${ }^{20}$. Table 11 depicts cross-country differences in the impact of sentiment, and the results of the significance of the difference between the coefficients shown in Table 6 computed by an additional bootstrap procedure ${ }^{21}$.

Table 11 shows that, independently of the choice of sentiment index (BW or EU), the highest/lowest dispersion is not always associated with the strongest/weakest sentiment

\footnotetext{
20 Obtained by testing for differences of means between markets.

${ }^{21}$ After resampling the series of bootstrap coefficients (10,000 times), the average values of which are shown in

Table 6 ,we compute the differences and the simulated p-value for the null hypothesis that: "the highest dispersion is associated with the strongest sentiment effect".
} 
effect. In terms of the BTM ratio, use of the BW index yields the expected relationship, but the differences are significant only when comparing France and the UK with Spain, which is where one would expect to find the weakest sentiment. Furthermore, use of the EU sentiment index yields no significant differences in any case. Size, both with the BW and the EU index, shows the expected results only for the UK, where the highest impact was to be expected, in relation to the rest. In the volatility and dividend portfolios, the highest dispersion in data corresponds to France, not Germany, which is the country with the highest estimated sentiment coefficient. Furthermore, the sentiment effet is not significantly weaker in Spain, which shows the least data dispersion, than in France, which shows the highest. No significant differences between the various countries are found when using the EU sentiment index.

Thus, the link between the highest/lowest level of dispersion in the various stock characteristics and the strongest/weakest sentiment effect in the differential portfolios is somewhat tenuous, thus ruling out stock characteristics as the single key factor behind the different levels of sentiment effect in these four markets, and suggesting that countryspecific factors may also influence results ${ }^{22}$.

Investor sentiment therefore influences asset prices both through characteristics, such as subjective valuation and limits to arbitrage, and through country-specific cultural and institutional factors. This has implications for studies using data from several countries but focusing on only one of these dimensions (stock characteristics or country-specific factors) without controlling for the other, when the results are subject to bias due to dispersion in the unobserved dimension.

\section{ROBUSTNESS TEST}

\subsection{Direct measures of investor sentiment}

In this section, we use direct measures of investor sentiment to test the robustness of the results to the choice of investor sentiment proxy. We use Investor Intelligence (II) as a

\footnotetext{
${ }^{22}$ The limitation of the analysis to only four countries in order to control for the level of market development makes it difficult to draw conclusions about the role of country-specific factors. Despite these limitations, the countries were characterised by four specific factors: two of them cultural (uncertainty avoidance index and individualism constructed by Hofstede, 2001) and two relating to market integrity (anti-director rights and accounting standards). Assignation to groups was based on the median. In two factors (uncertainty avoidance index and anti-director rights) we found investor sentiment to have different degrees of impact on the portfolios analyzed. This finding strengthens our previous evidence concerning the specific role of cultural and institutional factors in the impact of investor sentiment on stock returns.
} 
proxy for investor sentiment in the US market, and Sentix EuroStoxx 50 as a proxy for investor sentiment in Europe ${ }^{23}$.

With these data, we repeat the analysis of the relative role of stock characteristics using the multilevel regression method, to enable us to isolate this effect from the country effect. The results are shown in Table 12. By controlling for country specific effects, we show that stock characteristics play a very relevant role in explaining the impact of investor sentiment on stock returns. In fact, the results obtained with the II index are quite similar to those obtained with the BW index, except for the portfolios based on dividends, which lack significance. The results based on the Sentix index show more significance than those based on the SENT EU index, where the effect on the volatility portfolio is significant. Having confirmed the effect of stock characteristics, we continue the analysis by investigating the additional possibility of a country effect. We do this by testing for a significant positive relationship between divergence of characteristics and the sentiment effect, under the assumption that the role of institutional and cultural factors is nonexistent or barely relevant. However, as can be seen from Table 13, the relationship between the dispersion of the stock characteristic and the level of sentiment is in no way monotonic. In fact, in the analysis using the II variable, the only return different from zero is that of the volatility portfolio and the only significant result is counter to expectations. The analysis using the Sentix index reveals no significant between-country variation. In short, although the findings are somewhat different from those obtained using alternative proxies for investor sentiment, the main conclusion holds: stock characteristics are very important but they are not the only key variable in explaining the effect of investor sentiment on stock returns. Thus, the results have shown that both stock characteristics and country-specific cultural and institutional factors play an important role in explaining the impact of investor sentiment on stock returns. The fact that our choice of countries avoids widely differing levels of financial development, which could hamper the drawing of clear conclusions, makes these findings all the more relevant.

\subsection{Variables used to construct composite index proxies}

The choice of measures used to construct the composite index proxies for investor sentiment may alter their values, thus affecting the estimated impact of these proxies on stocks or portfolios. Observation has in fact shown that the results for two of the measures used in the index (BW and SENT EU) do not fully coincide. This section tests the results for robustness towards variations of composition on sentiment indexes. The observed

\footnotetext{
${ }_{23}^{23}$ The data were drawn from Datastream. These indices capture market sentiment well because they are calculated from a direct survey on the expected future state of the market. Sentix index data are available for the period 2001-2007.
} 
sentiment effect is stronger when using the BW factor than when using the EU factor. Therefore, the first issue to explore is whether this is because the US market has a higher capacity to generate information and convey sentiment or because the BW factor involves a greater number of variables, particularly of the kind described in the literature as proxies of "hot market" moments, such as IPOs. To answer this question, we recalculate the US market index using only the three measures included in the SENT EU index. Likewise, given the availability of some partial IPO data for the Spanish and UK markets, we perform a complementary test constructing the European indicator using very similar measures as for the BW index.

In the first test, the composite index is constructed from the same three measures used for the SENT EU index, except that the volatility premium is replaced with the dividend premium. The latter was included in the original BW index (Baker and Wurgler, 2006), and later replaced in Baker et al. (2012) with the volatility premium for the construction of the indices for the European markets. The other two measures are the University of Michigan Consumer Confidence Index ${ }^{24}$, as an equivalent of the European Commission Consumer Confidence Index, and turnover. This information is taken from Wurgler's web site.

Principal components analysis provides the first factor for this new indicator, which captures $59.640 \%$ of the variance ${ }^{25}$. The new condensed BW index, denoted below as SENT US ${ }^{26}$ is calculated according to the following expression:

SENT US $_{\mathrm{t}}=0.458$ CCMICH $_{\mathrm{t}-1}+0.403$ TURN $_{\mathrm{t}-1}-0.433$ DIVP $_{\mathrm{t}-1}$

To compare these results against the findings of the previous analysis, we reestimate the previous system of equations using the new SENT US. Table 14 shows the results of the effect of this new indicator on the stock characteristics. As can be seen, the coefficients estimated for this new index are lower than for the BW index, and closer to those obtained for the SENT EU index. This is particularly noticeable for France and Spain. The omission of key variables in the construction of the index therefore has noticeable effects on the findings. This suggests that the greater predictive power of the BW index very probably is due to its ability to capture more and better information about sentiment than the SENT EU index and not necessarily to the fact that it proxies for a market that generates more information of worldwide interest.

\footnotetext{
${ }^{24} \mathrm{http}: / /$ research.stlouisfed.org/fred2/series/UMCSENT/downloaddata?cid=98

${ }^{25}$ The correlation between the 6-term first-stage and the SENT US is 0.892 .

${ }^{26}$ This new index has positive correlation (0.811) statistically significant at the $1 \%$ level with the BW index.
} 
The second complementary test aims to complete, as far as possible, the set of measures used to construct a new sentiment indicator for the European Union. This additional information refers to IPOs for the UK and Spanish stock markets ${ }^{27}$. The result is two new composite indexes for the UK (SENT UK NIPO) and Spain (SENT SP IPO) which have the following form:

SENT UK NIPO $_{\mathrm{t}}=0.338 \mathrm{CC}_{\mathrm{t}-1}-0.544 \mathrm{TURN}_{\mathrm{t}}+0.103 \mathrm{VP}_{\mathrm{t}-1}+0.477 \mathrm{NIPO}_{\mathrm{t}-1}$

SENT SP IPO t $=0.342 \mathrm{CC}_{\mathrm{t}-1}-0.293 \mathrm{TURN}_{\mathrm{t}}+0.284 \mathrm{VP}_{\mathrm{t}-1}+0.241 \mathrm{NIPO}_{\mathrm{t}-1}+0.236 \mathrm{RIPO}_{\mathrm{t}-1}(10)$

From the new indexes for UK and Spain and the two original indexes for Germany and France, we derive a composite index for the European Union with $51.870 \%$ of the variance explained. This new index, denoted below by SENT EU IPO takes the following form:

SENT EU IPO $_{\mathrm{t}}=0,274$ SENT UK NIPO $_{\mathrm{t}}+0,431$ SENT GE $_{\mathrm{t}}+0,328$ SENT FR $_{\mathrm{t}}+0.337$ SENT $^{-0,0}$ $\mathrm{SPIPO}_{\mathrm{t}}(11)$

This new index shows positive (0.920) and significant correlation with the above SENT EU index. The new indexes constructed for the UK and Spain, and the original indexes for Germany and France all show positive and significant correlation with the new composite SENT EU IPO index.

Implementation of the estimation method using this index and the portfolios constructed in section 4 yields somewhat different results. Table 14 also shows the estimates given by the two variables (SENT EU IPO and SENT EU) for the same period (1996-2007). The results show that the incorporation of IPO data has an impact, particularly in the UK market, where size and high-low BTM portfolios becomes significant, and also in the Spanish market, where the medium-low BTM and the volatility portofolios gain significance. There is also an increase in the influence of this same variable on the results for France, where the volatility and the dividend portfolios become significant, and for Germany, where the high-low portfolio is significant. It appears therefore that the introduction of even a small amount of relevant data has a significant effect on the results.

The results of both these tests lead to two important conclusions. The first is that the results are sensitive to the choice of indicators for the construction of the sentiment index. The second is that, unless sentiment indexes for different countries or geographical areas incorporate exactly the same variables, it is not possible to conclude which is the most

\footnotetext{
${ }^{27}$ Data for the number of monthly IPOs and average first-day IPO returns were available for the Spanish market, but, given the scarcity of IPOs in the Spanish stock market, this paper uses average monthly returns for a 6 month period. Although various other possibilities were considered, observation showed this index to reflect market trends quite well. The data for the UK market are limited to the number of IPOs, which is high enough to require no adjustment. The data were supplied by the London Stock Exchange and the Madrid Bolsa, where they have been available since June, 1995.
} 
appropiate index, without adding the caveat that the difference may simply be due to the different explanatory power of the index variables in each case.

\section{CONCLUSIONS}

In this paper, we focus only on European markets because we wish to control for the level of financial development. The separate analysis of these four markets shows that investor sentiment has a significant effect on the future returns of stocks that are hard to value and more costly and risky to arbitrage. Nevertheless, the results differ across the countries considered and they highlight the sensitivity of the results to the choice of sentiment index. The study subsequently analyzes the role played by stock characteristics and countryspecific factors in explaining this effect. By controlling for country-specific effects, we find that stock characteristics are very relevant in explaining the effect of investor sentiment on stock returns. Nevertheless, we find that they are not the only variable underlying crosscountry differences in sentiment effects, since other factors, such as cultural or institutional differences may also play a key role. This suggests potential bias in the results of studies that consider several countries without controlling for one or other of these dimensions, since both are sources of investor sentiment.

The importance of the choice of sentiment proxy is also very evident. Overall, the results obtained using the proxy developed by Baker and Wurgler (2006) are the clearest in revealing the effect of investor sentiment on sentiment-sensitive stock. However, the choice of variables for the construction of the proxy also plays a key role, as revealed by the considerable difference in results that takes place after adding or removing certain variables. Due to some missing data for the European markets considered, there are differences in the construction of the BW and SENT EU indices. In light of the sensitivity of the results to the choice of index variables, therefore, we are unable to confirm whether the reason for the greater explanatory capacity of the BW index is that the US market is a greater generator and spreader of investor sentiment or simply that the data used to construct the European indices lacks sufficient richness. The results using direct measures of investor sentiment, while showing some sensitivity to the choice of proxy, lead to similar conclusions.

The direction of future research needs to be towards obtaining an objective, uniformly constructed variable, particularly to investigate the way sentiment spreads and assess the explanatory capacity of global and local sentiment indices, since differences in variable construction can have considerable impact on the results obtained.

\section{ACKNOWLEDGEMENTS}

This paper has received financial support from the Spanish Ministry of Science and Innovation (ECO2009-12819) and from the Spanish Ministry of Economy and Competitiveness (ECO2012-35946-C02-01). We would like to thank anonymous referees 
and the editor Carl R. Chen for their helpful comments and suggestions. We also like to thank participants at the $34^{\text {th }}$ European Accounting Association (EAA) Annual Congress, European Financial Management Association (EFMA) 2011 Annual Meeting and 2011 ACEDE Congress for helpful comments. Finalist for Best Paper Award, 2011 ACEDE Congress.

\section{REFERENCES}

Ahn, C., Lee, E-B., \& Suh, E-H., (2002). Noise trading in the Korean foreign exchange market: some questionnaire evidence, Bank of Korea Economic Papers, 5, 2, 133-155. Baker, M., \& Wurgler, J., (2000). The equity share in new issues and aggregate stock returns, Journal of Finance, 55, 2219-2257.

Baker, M., \& Wurgler, J., (2004a). A catering theory of dividends, Journal of Finance, 59, 3, 1125-1165.

Baker, M., \& Wurgler, J., (2004b). Appearing and disappearing dividends: the link to catering incentives, Journal of Financial Economics, 73, 2, 271-288.

Baker, M., \& Wurgler, J., (2006). Investor sentiment and the cross-section of stock returns, Journal of Finance, 61, 4, 1645-1680.

Baker, M., \& Wurgler, J., (2007). Investor sentiment in the stock market, Journal of Economic Perspectives, 21, 2, 129-151.

Baker, M., Wurgler, J., \& Yu, Y., (2012). Global, local, and contagious investor sentiment, Journal of Financial Economics, 104, 272-287.

Baker, M., \& Stein, J., (2004). Market liquidity as a sentiment indicator, Journal of Financial Markets, 7, 271-299.

Barber, B. M., Odean, T., \& Zhu, N., (2006). Systematic noise, Journal of Financial Markets, 12, 547-569.

Brown, G. W., \& Cliff, M. T., (2004). Investor sentiment and the near-term stock market, Journal of Empirical Finance, 11, 1-27.

Brown, G. W., \& Cliff, M. T., (2005). Investor sentiment and asset valuation, Journal of Business, 78, 2, 405-440.

Brown, S., Goetzmann, W. N., Hiraki, T., Shiraishi, N., \& Watanabe, M., (2003). Investor sentiment in Japanese and U.S. daily mutual fund flows, NBER Working Paper 9470, http://www.nber.org/papers/w9470.

Burghardt, M., Czink, M., \& Riordan, R., (2008). Retail investor sentiment and the stock market, Available at SSRN:http://ssrn.com/abstract=1100038 or http://dx.doi.org/10.2139/ssrn.1100038. 
Chang, Y. Y., Faff, R., \& Hwang, C-Y., (2012). Local and global sentiment effects, and the role of legal, information and trading, Available at SSRN: http://ssrn.com/abstract=1800550 or http://dx.doi.org/10.2139/ssrn.1800550.

Chiou, W-J. P., Lee, A.C., \& Lee, C-F. (2010). Stock return, risk, and legal environment around the world, International Review of Economics and Finance, 19, 95-105.

Chui, A. C. W., Titman, S., \& Wei, K. C. J., (2010). Individualism and momentum around the World, Journal of Finance, 65, 361-392.

Doukas, J. A., \& Milonas, N. T., (2004). Investor sentiment and the closed-end fund puzzle: out-of-sample evidence, European Financial Management, 10, 235-266.

Fama, E. F., \& French, K. R., (1993). Common risk factors in the returns on stocks and bonds, Journal of Financial Economics, 33, 3-56.

Fisher, K.L., \& Statman, M., (2000). Investor sentiment and stock returns, Financial Analysts, (March-April), 16-23

Frazzini, A., \& Lamont, O., (2008). Dumb Money: mutual fund flows and the cross-section of stock returns, Journal of Financial Economics, 88, 2, 299-322.

Greenwood, R., and Nagel, S., (2006). Inexperienced investors and bubbles, http://www.people.hbs.edu/rgreenwood/Mfage8.pdf.

Gutierrez, J.A., Martinez, V., \& Yuman T. (2009). Where does return and volatility come from? The case of Asian ETFs, International Review of Economics and Finance, 18, 671-679. Han, B., (2008). Investor sentiment and option prices, Review of Financial Studies, 21, 1, 387-414.

Ho, Ch., \& Hung, Ch. (2009). Investor sentiment as conditioning information in asset pricing, Journal of Banking and Finance, 33, 892-903.

Hofstede, G., (2001). Culture's consequences: comparing values, behaviors, institutions, and organizations across nations, Sage Publication, Beverly Hills.

Ince, O. S., \& Porter, R. B., (2006). Individual equity return data from Thomson Datastream: Handle with care!, Journal of Financial Research, 29, 463-479.

Jansen, W. J., \& Nahuis, N. J., (2003). The stock market and consumer confidence: European evidence, Economic Letters, 79, 89-98.

Jegadeesh, N., \& Titman, S., (2001). Profitability of momentum strategies: an evaluation of alternative explanations, Journal of Finance, 56, 2, 699-720.

Jones, C. M., (2002). A century of stock market liquidity and trading costs, Available at SSRN: http://ssrn.com/abstract=313681 or http://dx.doi.org/10.2139/ssrn.313681.

Kamstra, M. J., Kramer, L. A., \& Levi, M. D., (2003). Winter blues: a SAD stock market cycle, American Economic Review, 93, 1, 1257-1263.

Kothari, S. P., \& Shanken, J., (1997). Book-to-market, dividend yield, and expected market returns: A time-series analysis, Journal of Financial Economics, 44, 169-203.

Kumar, A., \& Lee, C., (2006). Retail investor sentiment and return comovement, Journal of Finance, 61, 5, 2451-2486. 
La Porta, F., López-de-Silanes, F., Shleifer, A., \& Vishny, R. W., (1998). Law and finance, Journal of Political Economy, 106, 1113-1155.

Lee, C., Shleifer, A., \& Thaler, R. H., (1991). Investor sentiment and the closed-end fund puzzle, Journal of Finance, 46, 75-109.

Lemmon, M., \& Ni, S. X., (2011). The effects of investor sentiment on speculative trading and prices of stock and index options, AFA 2011 Denver Meetings Paper. Available at SSRN: http://ssrn.com/abstract=1572427 or http://dx.doi.org/10.2139/ssrn.1572427.

Lemmon, M., \& Portniaguina, E., (2006). Consumer confidence and asset prices: some empirical evidence, Review of Financial Studies, 19, 4, 1499-1529.

Ljungqvist, A., Nanda, V., \& Singh, R., (2006). Hot markets, investor sentiment, and IPO pricing, Journal of Business, 79, 4, 1667-1703.

Neal, R., \& Wheatley, S. M., (1998). Do measures of investor sentiment predict returns?, Journal of Financial and Quantitative Analysis, 33, 4, 523-547.

Otoo, M. W., (1999). Consumer sentiment and the stock market, Working Paper. Federal Reserve Board of Governors.

Qiu, L., \& Welch, I., (2006). Investor sentiment measures, Available at SSRN:

http://ssrn.com/abstract=589641 or http://dx.doi.org/10.2139/ssrn.589641.

Scheinkman, J., \& Xiong, W., (2003). Overconfidence and speculative bubbles, Journal of Political Economy, 111, 6, 1183-1219.

Schmeling, M., (2009). Investor sentiment and stock returns: some international evidence, Journal of Empirical Finance, 16, 394-408.

Schmitz, P., Glaser, M., \& Weber, M., (2009). Individual investor sentiment and stock returns-What do we learn from warrant traders?, Available at SSRN: http://ssrn.com/abstract=923526 or http://dx.doi.org/10.2139/ssrn.923526.

Seyhun, H. N., (1998). Investment Intelligence from Insider Trading, MA: MIT Press, Cambridge.

Shiller, R. J., (1981). Do stock prices move too much to be justified by subsequent changes in dividends?, American Economic Review, 71, 421-436.

Shiller, R. J. (2000). Irrational Exuberance, Princeton UP, Princeton.

Solt, M.E., \& Statman, M., (1988). How useful is the sentiment index, Financial Analysts Journal, (September-October), 45-55.

Stambaugh, R. F., (1999). Predictive regressions, Journal of Financial Economics 54, 375421.

Swaminathan, B., (1996). Time-varying expected small firm returns and closed-end fund discounts, Review of Financial Studies, 9, 845-887.

Wang, C., (2001). Investor sentiment and return predictability in agricultural futures markets, Journal of Futures Markets, 21, 10, 929-952.

Wang, C., (2003). Investor sentiment, market timing and futures returns, Applied Financial Economics, 13, 12, 891-898. 
Wang, Y-H., Keswani, A., \& Taylor, S. J., (2006). The relationships between sentiment, returns and volatility, International Journal of Forecasting, 22, 109-123.

Whaley, R. E., (2000). The investor fear gauge, Journal of Portfolio Management, 26, 3, 12 17.

Zhu, M. (2012). Return distribution predictability and its implications for portfolio selection, International Review of Economics and Finance, in press, http://dx.doi.org/10.1013/j.iref.2012.10.002.

Zweig, M. E., (1973). An investor expectations stock price predictive model using closed-end fund premiums, Journal of Finance, 28, 1, 67-87.

Figure 1: Investor sentiment. Period 1992-2007.

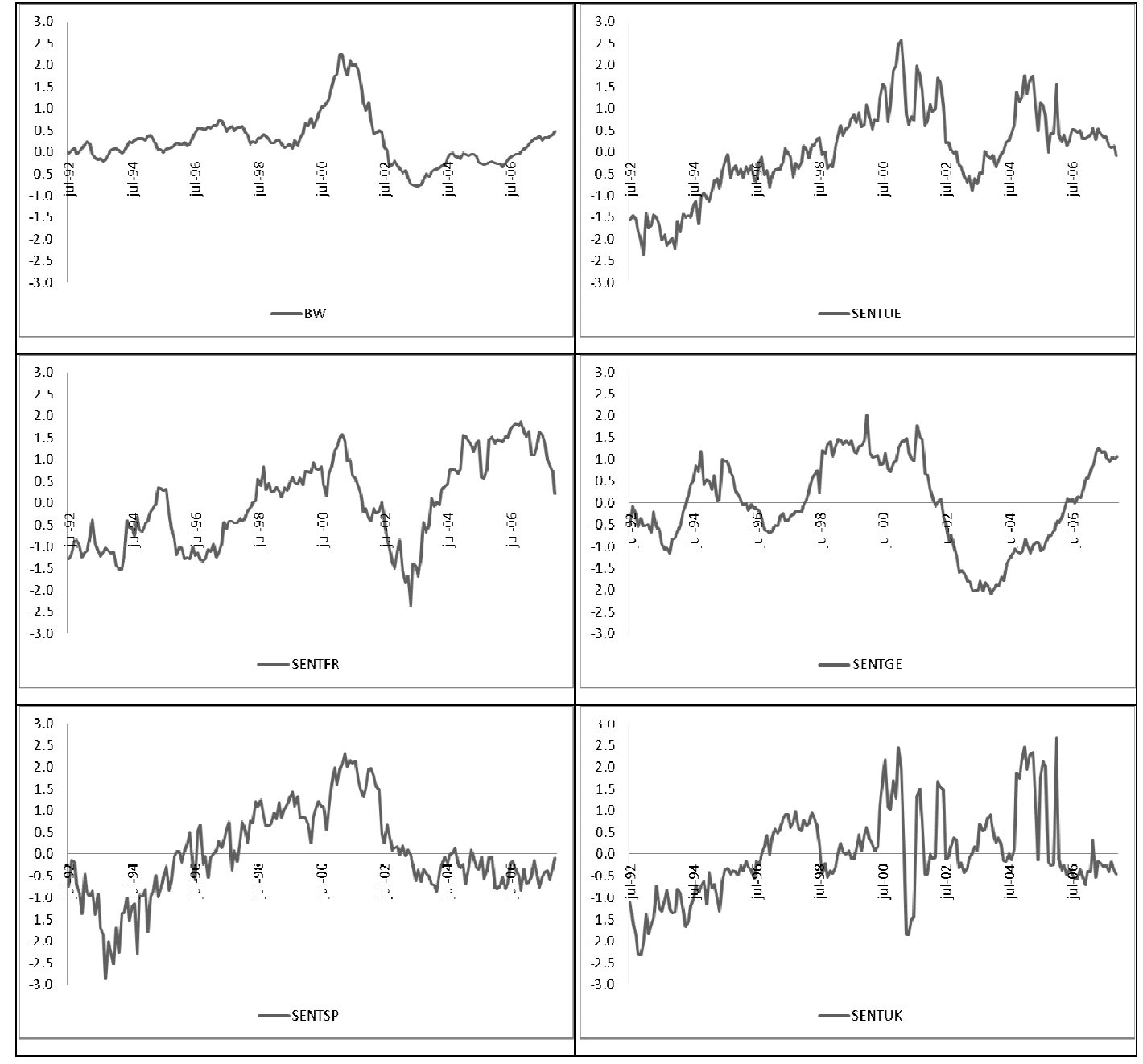

The graphs show the trend of the Baker and Wurgler (2006) index, the indices constructed for the four European markets and the composite index for the European Union. SENT SP, SENT UK, SENT GE and SENT FR are the first principal components of three sentiment indicators. SENT EU is the first principal component of the first factors extracted for each of the four European markets. 
Table 1: Descriptive statistics of the stock characteristics. 1990-2007.

\begin{tabular}{|c|c|c|c|c|}
\hline \multirow[t]{2}{*}{ FRANCE } & \multirow[b]{2}{*}{ Mean } & \multicolumn{3}{|c|}{ Mean } \\
\hline & & $\mathrm{SD}$ & $1990 \mathrm{~s}$ & $2000 \mathrm{~s}$ \\
\hline BTM & 0.83 & 1.50 & 0.92 & 0.76 \\
\hline SIZ & 1231.28 & 6265.42 & 798.68 & 1562.88 \\
\hline VOL (\%) & 12.76 & 12.09 & 10.90 & 14.25 \\
\hline DIV & 1.61 & 8.03 & 1.53 & 1.67 \\
\hline \multicolumn{5}{|l|}{ GERMANY } \\
\hline & Mean & $\mathrm{SD}$ & & \\
\hline BTM & 1.98 & 6.44 & 0.62 & 2.25 \\
\hline SIZ & 1234.53 & 6311.79 & 2102.79 & 1057.04 \\
\hline VOL (\%) & 15.82 & 12.52 & 10.76 & 16.73 \\
\hline DIV & 0.43 & 1.63 & 0.70 & 0.38 \\
\hline \multicolumn{5}{|l|}{ SPAIN } \\
\hline & Mean & $\mathrm{SD}$ & & \\
\hline BTM & 0.78 & 0.98 & 0.94 & 0.63 \\
\hline $\mathrm{SIZ}$ & 2357.12 & 7452.98 & 1138.10 & 3592.67 \\
\hline VOL (\%) & 9.21 & 6.30 & 10.57 & 7.98 \\
\hline DIV & 0.28 & 0.91 & 0.26 & 0.31 \\
\hline \multicolumn{5}{|l|}{ UK } \\
\hline & Mean & $\mathrm{SD}$ & & \\
\hline BTM & 0.76 & 1.11 & 0.76 & 0.77 \\
\hline $\mathrm{SIZ}$ & 1126.79 & 7069.65 & 856.57 & 1375.52 \\
\hline VOL (\%) & 12.36 & 8.91 & 10.63 & 13.76 \\
\hline DIV & 9.24 & 26.24 & 9.50 & 8.89 \\
\hline
\end{tabular}

Means and standard deviations of the stock characteristics for Spain, the UK, Germany and

France. The book-to-market ratio (BTM) is the ratio between the two values at the end of each month. Size (SIZ) is the end-of-month stock market capitalization of each firm in thousands of Euros. Volatility (VOL) is the last twelve months' standard deviation in percentage terms. Dividend (DIV) is the end of month dividend per share ratio. 
Table 2: Country-specific sentiment. 1992-2007.

\begin{tabular}{|c|c|c|c|c|c|c|c|c|c|c|c|c|}
\hline & \multicolumn{3}{|c|}{ Descriptive statistics } & \multicolumn{2}{|c|}{ Correlations } & \multicolumn{7}{|c|}{ Correlations between each sentiment indicator } \\
\hline & Mean & SD & Min & Max & Coef. & $\mathrm{p}$-value & $\mathrm{CC}$ & & TURN & & $\mathrm{PV}$ & \\
\hline FRANCE & & & & & & & Coef. & $\mathrm{p}$-value & Coef. & $\mathrm{p}$-value & Coef. & $\mathrm{p}$-value \\
\hline $\mathrm{CC}_{\mathrm{t}}$ & -16.07 & 8.92 & -35.00 & 3.30 & 0.77 & 0.00 & 1.00 & & & & & \\
\hline TURN $_{\mathrm{t}-1}$ & 0.14 & 1.17 & -1.40 & 5.11 & -0.56 & 0.00 & -0.16 & 0.03 & 1.00 & & & \\
\hline $\mathrm{VP}_{\mathrm{t}-1}$ & 0.64 & 0.86 & -1.13 & 2.78 & 0.82 & 0.00 & 0.44 & 0.00 & -0.25 & 0.00 & 1.00 & \\
\hline \multicolumn{13}{|l|}{ GERMANY } \\
\hline $\mathrm{CC}_{\mathrm{t}}$ & -10.09 & 9.20 & -27.50 & 10.20 & 0.77 & 0.00 & 1.00 & & & & & \\
\hline TURN ${ }_{t-1}$ & -0.12 & 0.52 & -1.54 & 1.32 & 0.89 & 0.00 & 0.51 & 0.00 & 1.00 & & & \\
\hline $\mathrm{VP}_{\mathrm{t}-1}$ & 1.37 & 1.60 & -3.01 & 5.36 & 0.46 & 0.00 & 0.02 & 0.82 & 0.29 & 0.00 & 1.00 & \\
\hline \multicolumn{13}{|l|}{ SPAIN } \\
\hline $\mathrm{CC}_{\mathrm{t}-1}$ & -10.51 & 9.52 & -38.60 & 5.30 & 0.89 & 0.00 & 1.00 & & & & & \\
\hline TURN $_{\mathrm{t}}$ & 0.07 & 0.53 & -1.00 & 2.03 & -0.81 & 0.00 & -0.62 & 0.00 & 1.00 & & & \\
\hline $\mathrm{VP}_{\mathrm{t}-1}$ & 0.21 & 0.40 & -0.49 & 1.40 & 0.80 & 0.00 & 0.60 & 0.00 & -0.43 & 0.00 & 1.00 & \\
\hline \multicolumn{13}{|l|}{ UK } \\
\hline $\mathrm{CC}_{\mathrm{t}}$ & -6.09 & 6.83 & -29.40 & 7.10 & 0.71 & 0.00 & 1.00 & & & & & \\
\hline TURN ${ }_{\mathrm{t}-1}$ & 0.17 & 0.90 & -0.97 & 3.75 & 0.68 & 0.00 & 0.14 & 0.05 & 1.00 & & & \\
\hline $\mathrm{VP}_{\mathrm{t}-1}$ & 0.55 & 2.33 & -10.08 & 10.37 & 0.46 & 0.00 & 0.07 & 0.33 & 0.05 & 0.51 & 1.00 & \\
\hline
\end{tabular}

The first four columns display the descriptive statistics of the sentiment indicators used to construct the four country-specific sentiment indices. The next two columns show the correlation between each sentiment indicator and each country-specific sentiment index. The last six columns show the correlation between the variables included in the formation of the principal components of each country. The consumer confidence index (CC) is a public index based on direct surveys conducted by the European Commission at each month end. Turnover (TURN) is measured as the natural log of the raw turnover ratio, detrended by the five year moving average. The volatility premium (VOL) is the log of the average book-to-market ratio with high and low volatility. 
Table 3: Correlations between the sentiment indices. Period 1992-2007.

\begin{tabular}{|c|c|c|c|c|c|c|c|}
\hline & & SENT FR & SENT GE & SENT SP & SENT UK & SENT EU & BW \\
\hline SENT FR & $\begin{array}{r}\text { Coef. } \\
\text { p-value }\end{array}$ & 1.00 & & & & & \\
\hline \multirow[t]{2}{*}{ SENT GE } & Coef. & 0.43 & 1.00 & & & & \\
\hline & $\mathrm{p}$-value & 0.00 & & & & & \\
\hline \multirow[t]{2}{*}{ SENT SP } & Coef. & 0.27 & 0.45 & 1.00 & & & \\
\hline & $\mathrm{p}$-valor & 0.00 & 0.00 & & & & \\
\hline \multirow[t]{2}{*}{ SENT UK } & Coef. & 0.30 & -0.07 & 0.37 & 1.00 & & \\
\hline & $\mathrm{p}$-value & 0.00 & 0.35 & 0.00 & & & \\
\hline \multirow[t]{2}{*}{ SENT EU } & Coef. & 0.74 & 0.70 & 0.78 & 0.51 & 1.00 & \\
\hline & $\mathrm{p}$-value & 0.00 & 0.00 & 0.00 & 0.00 & & \\
\hline \multirow[t]{2}{*}{ BW } & Coef. & 0.24 & 0.66 & 0.63 & 0.13 & 0.62 & 1.00 \\
\hline & $\mathrm{p}$-value & 0.00 & 0.00 & 0.00 & 0.09 & 0.00 & \\
\hline
\end{tabular}

This table shows the correlations between Baker and Wurgler's (2006) index, the 4 country-specific indexes and the composite European index. SENT SP, SENT UK, SENT GE and SENT FR are the first principal components of the three sentiment indicators. SENT EU is the first principal component of the first factors of the four country-specific indexes. 
Table 4: Granger-causality tests

\begin{tabular}{|c|c|c|c|c|c|c|c|c|}
\hline & \multicolumn{2}{|c|}{ FRANCE } & \multicolumn{2}{|c|}{ GERMANY } & \multicolumn{2}{|c|}{ SPAIN } & \multicolumn{2}{|c|}{ UK } \\
\hline & $\mathrm{BW} \rightarrow$ Ret & Ret $\rightarrow$ BW & $\mathrm{BW} \rightarrow$ Ret & Ret $\rightarrow$ BW & $\mathrm{BW} \rightarrow$ Ret & Ret $\rightarrow$ BW & $\mathrm{BW} \rightarrow$ Ret & Ret $\rightarrow$ BW \\
\hline BTM & 0.4288 & 0.0485 & 0.1714 & 0.7073 & 0.3941 & 0.2182 & 0.0397 & 0.3113 \\
\hline SMB & 0.9108 & 0.6453 & 0.116 & 0.5074 & 0.9903 & 0.1197 & 0.0019 & 0.6706 \\
\hline VOL & 0.0397 & 0.6221 & 0.0096 & 0.7814 & 0.137 & 0.6461 & 0.0019 & 0.6706 \\
\hline \multirow[t]{2}{*}{ DIV } & 0.1181 & 0.9006 & 0.0005 & 0.8208 & 0.0148 & 0.2723 & 0.0009 & 0.4161 \\
\hline & $\mathrm{UE} \rightarrow$ Ret & Ret $\rightarrow \mathrm{UE}$ & $\mathrm{UE} \rightarrow$ Ret & Ret $\rightarrow \mathrm{UE}$ & $\mathrm{UE} \rightarrow$ Ret & Ret $\rightarrow \mathrm{UE}$ & $\mathrm{UE} \rightarrow \operatorname{Ret}$ & Ret $\rightarrow \mathrm{UE}$ \\
\hline BTM & 0.0114 & 0.7841 & 0.4141 & 0.521 & 0.2641 & 0.3539 & 0.7524 & 0.5143 \\
\hline SMB & 0.3148 & 0.1419 & 0.7975 & 0.8444 & 0.8456 & 0.1369 & 0.0165 & 0.0009 \\
\hline VOL & 0.5404 & 0.0158 & 0.3843 & 0.1206 & 0.8581 & 0.001 & 0.1626 & 0.008 \\
\hline DIV & 0.9263 & 0.2686 & 0.5923 & 0.3215 & 0.8759 & 0.007 & 0.3893 & 0.0014 \\
\hline
\end{tabular}

This table shows the Granger-causality tests (p-value) for sentiment (BW and UE) and returns of diferent portfolios (BTM, size, volatility and dividends). Results are obtained from VAR models wich include returns, sentiment and macroeconomic variables. The lag length is chosen by minimizing Schwarz. 
Table 5: Correlations between portfolio returns. 1990-2007.

\begin{tabular}{|c|c|c|c|c|c|c|c|c|c|c|c|c|c|c|c|}
\hline FRANCE & & BTM (H-L) & BTM (M-L) & BTM (H-M) & SIZ (S-B) & VOL (H-L) & DIV (H-L) & GERMANY & & BTM (H-L) & BTM (M-L) & BTM (H-M) & SIZ (S-B) & VOL (H-L) & DIV (H-L) \\
\hline BTM (H-L) & $\begin{array}{l}\text { Coef. } \\
\text { p-value }\end{array}$ & 1.00 & & & & & & BTM (H-L) & $\begin{array}{r}\text { Coef. } \\
\text { p-value }\end{array}$ & 1.00 & & & & & \\
\hline \multirow[t]{2}{*}{ BTM (M-L) } & Coef. & 0.90 & 1.00 & & & & & BTM (M-L) & Coef. & 0.76 & 1.00 & & & & \\
\hline & $\mathrm{p}$-value & 0.00 & & & & & & & $\mathrm{p}$-value & 0.00 & & & & & \\
\hline \multirow[t]{2}{*}{ BTM (H-M) } & Coef. & 0.72 & 0.34 & 1.00 & & & & BTM (H-M) & Coef. & 0.79 & 0.20 & 1.00 & & & \\
\hline & $\mathrm{p}$-value & 0.00 & 0.00 & & & & & & $\mathrm{p}$-value & 0.00 & 0.00 & & & & \\
\hline \multirow[t]{2}{*}{ SIZ (S-B) } & Coef. & 0.26 & 0.03 & 0.52 & 1.00 & & & SIZ (S-B) & Coef. & 0.46 & 0.09 & 0.61 & 1.00 & & \\
\hline & $\mathrm{p}$-value & 0.00 & 0.70 & 0.00 & & & & & $\mathrm{p}$-value & 0.00 & 0.21 & 0.00 & & & \\
\hline \multirow[t]{2}{*}{ VOL (H-L) } & Coef. & -0.59 & -0.66 & -0.21 & 0.18 & 1.00 & & VOL (H-L) & Coef. & -0.29 & -0.48 & 0.01 & 0.38 & 1.00 & \\
\hline & $\mathrm{p}$-value & 0.00 & 0.00 & 0.00 & 0.02 & & & & $\mathrm{p}$-value & 0.00 & 0.00 & 0.87 & 0.00 & & \\
\hline \multirow[t]{2}{*}{ DIV (H-L) } & Coef. & 0.62 & 0.67 & 0.25 & -0.20 & -0.87 & 1.00 & DIV (H-L) & Coef. & 0.35 & 0.48 & 0.07 & -0.36 & -0.87 & 1.00 \\
\hline & $\mathrm{p}$-value & 0.00 & 0.00 & 0.00 & 0.00 & 0.00 & & & $\mathrm{p}$-value & 0.00 & 0.00 & 0.32 & 0.00 & 0.00 & \\
\hline SPAIN & & BTM (H-L) & BTM (M-L) & BTM (H-M) & SIZ (S-B) & VOL (H-L) & DIV (H-L) & UK & & BTM (H-L) & BTM (M-L) & BTM (H-M) & SIZ (S-B) & VOL (H-L) & DIV (H-L) \\
\hline BTM (H-L) & $\begin{array}{l}\text { Coef. } \\
\text { p-value }\end{array}$ & 1.00 & & & & & & BTM (H-L) & $\begin{array}{r}\text { Coef. } \\
\text { p-value }\end{array}$ & 1.00 & & & & & \\
\hline \multirow[t]{2}{*}{ BTM (M-L) } & Coef. & 0.58 & 1.00 & & & & & BTM (M-L) & Coef. & 0.90 & 1.00 & & & & \\
\hline & $\mathrm{p}$-value & 0.00 & & & & & & & $\mathrm{p}$-value & 0.00 & & & & & \\
\hline \multirow[t]{2}{*}{ BTM (H-M) } & Coef. & 0.64 & -0.25 & 1.00 & & & & BTM (H-M) & Coef. & 0.64 & 0.24 & 1.00 & & & \\
\hline & $\mathrm{p}$-value & 0.00 & 0.00 & & & & & & $\mathrm{p}$-value & 0.00 & 0.00 & & & & \\
\hline \multirow[t]{2}{*}{ SIZ (S-B) } & Coef. & 0.50 & 0.02 & 0.58 & 1.00 & & & SIZ (S-B) & Coef. & -0.01 & -0.25 & 0.42 & 1.00 & & \\
\hline & $\mathrm{p}$-value & 0.00 & 0.82 & 0.00 & & & & & $p$-value & 0.90 & 0.00 & 0.00 & & & \\
\hline \multirow[t]{2}{*}{ VOL (H-L) } & Coef. & -0.06 & -0.49 & 0.41 & 0.51 & 1.00 & & VOL (H-L) & Coef. & -0.65 & -0.69 & -0.23 & 0.41 & 1.00 & \\
\hline & $\mathrm{p}$-value & 0.45 & 0.00 & 0.00 & 0.00 & & & & $\mathrm{p}$-value & 0.00 & 0.00 & 0.00 & 0.00 & & \\
\hline \multirow[t]{2}{*}{ DIV (H-L) } & Coef. & -0.05 & 0.42 & -0.45 & -0.62 & -0.79 & 1.00 & DIV (H-L) & Coef. & 0.58 & 0.72 & 0.02 & -0.70 & -0.81 & 1.00 \\
\hline & $\mathrm{p}$-value & 0.50 & 0.00 & 0.00 & 0.00 & 0.00 & & & $\mathrm{p}$-value & 0.00 & 0.00 & 0.77 & 0.00 & 0.00 & \\
\hline
\end{tabular}

Correlations between the four characteristic portfolios: book-to-market ratio (BTM), sixe (SIZ), volatility (VOL) and dividend (DIV) and the four European markets: Spain, The UK, Germany and France. High (H)/big

(B) were constructed from the top $20 \%$ and low (L)/small (S) from the bottom $20 \%$. Medium (M) was constructed from the stocks in the third quintile. The differential portfolio of any given month was computed as in

Jegadeesh and Titman (2001). 
Table 6: Regressions of the portfolio returns.

\begin{tabular}{|c|c|c|c|c|c|c|c|c|c|c|c|c|c|}
\hline \multirow[b]{3}{*}{ FRANCE } & \multirow[b]{3}{*}{ ES } & \multicolumn{6}{|c|}{ BW } & \multicolumn{6}{|c|}{ SENT EU } \\
\hline & & \multicolumn{2}{|c|}{$6 \mathrm{M}$} & \multicolumn{2}{|c|}{$12 \mathrm{M}$} & \multicolumn{2}{|c|}{$24 \mathrm{M}$} & \multicolumn{2}{|c|}{$6 \mathrm{M}$} & \multicolumn{2}{|c|}{$12 \mathrm{M}$} & \multicolumn{2}{|c|}{$24 \mathrm{M}$} \\
\hline & & Coef. & $p$-value & Coef. & $\mathrm{p}$-value & Coef. & $p$-value & Coef. & $\mathrm{p}$-value & Coef. & $\mathrm{p}$-value & Coef. & $p$-value \\
\hline BTM (H-L) & + & 1.60 & 0.08 & 1.89 & 0.07 & 1.82 & 0.05 & -0.78 & 0.88 & -0.45 & 0.77 & -0.10 & 0.53 \\
\hline BTM (M-L) & + & 1.50 & 0.01 & 1.64 & 0.02 & 1.38 & 0.02 & -0.68 & 0.94 & -0.46 & 0.87 & -0.28 & 0.84 \\
\hline BTM (H-M) & - & 0.05 & 0.64 & 0.26 & 0.77 & 0.43 & 0.84 & -0.06 & 0.58 & 0.03 & 0.52 & 0.16 & 0.68 \\
\hline SIZ (S-B) & - & 0.48 & 0.80 & 0.74 & 0.89 & 0.86 & 0.88 & 0.45 & 0.84 & 0.69 & 0.84 & 0.76 & 0.86 \\
\hline VOL (H-L) & - & -2.22 & 0.04 & -2.17 & 0.04 & -1.95 & 0.03 & -0.51 & 0.28 & -0.49 & 0.82 & -0.50 & 0.27 \\
\hline DIV (H-L) & + & 1.47 & 0.03 & 1.55 & 0.02 & 1.45 & 0.03 & 0.12 & 0.39 & 0.14 & 0.41 & 0.12 & 0.41 \\
\hline GERMANY & $\mathrm{ES}$ & Coef. & $p$-value & Coef. & $\mathrm{p}$-value & Coef. & $\mathrm{p}$-value & Coef. & $\mathrm{p}$-value & Coef. & $\mathrm{p}$-value & Coef. & $\mathrm{p}$-value \\
\hline BTM (H-L) & + & 1.86 & 0.14 & 2.50 & 0.09 & 2.83 & 0.05 & 0.58 & 0.25 & 0.70 & 0.23 & 0.80 & 0.17 \\
\hline BTM (M-L) & + & 0.74 & 0.13 & 0.70 & 0.16 & 0.78 & 0.18 & 0.11 & 0.43 & 0.14 & 0.38 & 0.13 & 0.38 \\
\hline BTM (H-M) & - & 1.29 & 0.89 & 1.68 & 0.93 & 2.03 & 0.98 & 0.44 & 0.88 & 0.55 & 0.87 & 0.65 & 0.94 \\
\hline SIZ (S-B) & - & -0.36 & 0.34 & 0.13 & 0.58 & 0.09 & 0.55 & 0.46 & 0.77 & 0.54 & 0.81 & 0.50 & 0.83 \\
\hline VOL (H-L) & - & -4.16 & 0.01 & -4.27 & 0.01 & -4.12 & 0.01 & -1.13 & 0.14 & -1.28 & 0.08 & -1.05 & 0.10 \\
\hline DIV (H-L) & + & 3.65 & 0.01 & 3.67 & 0.01 & 3.14 & 0.02 & 0.43 & 0.30 & 0.56 & 0.23 & 0.43 & 0.27 \\
\hline SPAIN & ES & Coef. & $\mathrm{p}$-value & Coef. & $\mathrm{p}$-value & Coef. & $p$-value & Coef. & $p$-value & Coef. & $\mathrm{p}$-value & Coef. & $\mathrm{p}$-value \\
\hline BTM (H-L) & + & 0.21 & 0.29 & 0.58 & 0.08 & 0.75 & 0.04 & 0.86 & 0.02 & 0.93 & 0.01 & 0.86 & 0.01 \\
\hline BTM (M-L) & + & 0.27 & 0.19 & 0.41 & 0.15 & 0.56 & 0.07 & 0.10 & 0.36 & 0.24 & 0.23 & 0.37 & 0.13 \\
\hline BTM (H-M) & - & -0.06 & 0.54 & 0.19 & 0.69 & 0.22 & 0.71 & 0.77 & 0.99 & 0.68 & 0.98 & 0.50 & 0.95 \\
\hline SIZ (S-B) & - & 0.12 & 0.59 & 0.35 & 0.73 & 0.54 & 0.83 & 0.73 & 0.90 & 0.77 & 0.92 & 0.68 & 0.90 \\
\hline VOL (H-L) & - & -1.05 & 0.08 & -1.24 & 0.03 & -1.15 & 0.06 & 0.12 & 0.56 & -0.01 & 0.53 & -0.08 & 0.58 \\
\hline DIV (H-L) & + & 1.78 & 0.01 & 1.59 & 0.03 & 1.21 & 0.06 & 0.19 & 0.38 & 0.19 & 0.37 & 0.07 & 0.43 \\
\hline UK & $\mathrm{ES}$ & Coef. & p-value & Coef. & $\mathrm{p}$-value & Coef. & $\mathrm{p}$-value & Coef. & $p$-value & Coef. & p-value & Coef. & $\mathrm{p}$-value \\
\hline BTM (H-L) & + & 2.22 & 0.03 & 2.49 & 0.02 & 2.41 & 0.01 & 0.50 & 0.18 & 0.61 & 0.15 & 0.55 & 0.15 \\
\hline BTM (M-L) & + & 1.81 & 0.03 & 1.88 & 0.02 & 1.88 & 0.01 & 0.42 & 0.17 & 0.52 & 0.13 & 0.53 & 0.10 \\
\hline BTM (H-M) & - & 0.42 & 0.92 & 0.58 & 0.96 & 0.54 & 0.93 & 0.03 & 0.56 & 0.03 & 0.58 & 0.01 & 0.55 \\
\hline SIZ (S-B) & - & -1.70 & 0.00 & -1.37 & 0.03 & -1.21 & 0.04 & -0.73 & 0.08 & -0.57 & 0.13 & -0.49 & 0.15 \\
\hline VOL (H-L) & - & -4.26 & 0.00 & -4.19 & 0.00 & -3.69 & 0.00 & -1.44 & 0.06 & -1.53 & 0.05 & -1.37 & 0.05 \\
\hline DIV (H-L) & + & 3.28 & 0.00 & 3.20 & 0.00 & 2.99 & 0.00 & 0.96 & 0.08 & 0.97 & 0.07 & 0.95 & 0.06 \\
\hline
\end{tabular}

Regressions of long-short portfolios constructed following the approach used by Jegadeesh and Titman (2001) for a 6, 12 and 24 month time horizon. Portfolios were constructed for Book-to-market ratio (BTM), size (SIZ), volatility (VOL) and dividend (DIV). The high (H)/big (B) portfolio was formed from the top $20 \%$ of the stocks and the low (L)/small (S) portfolio from those in the first quintile. The medium (M) portfolio was formed from the stocks in the third quintile. The sentiment indicators are Baker and Wurgler's (2006), BW index, constructed from the first principal component of 6 proxies, for the period 1990 to 2007 and the European investor sentiment index EU SENT, constructed from the first principal component of the first factors obtained for Spain, the UK, Germany and France for the period 1992 to 2007. These first factors explain the common variance of the three sentiment indexes. We use a block bootstrap method to compute the simulated p-value for the null hypothesis that the coefficient has the expected sign.The macroeconomic variables included are the industrial output index, durable goods consumption, consumer goods consumption and the unemployment index. 
Table 7: Regressions of the Fama-French portfolio returns.

\begin{tabular}{|c|c|c|c|c|c|c|c|c|c|c|c|c|c|}
\hline \multirow[b]{3}{*}{ FRANCE } & \multirow[b]{3}{*}{ ES } & \multicolumn{6}{|c|}{ BW } & \multicolumn{6}{|c|}{ SENT EU } \\
\hline & & \multicolumn{2}{|c|}{$6 \mathrm{M}$} & \multicolumn{2}{|c|}{$12 \mathrm{M}$} & \multicolumn{2}{|c|}{$24 \mathrm{M}$} & \multicolumn{2}{|c|}{$6 \mathrm{M}$} & \multicolumn{2}{|c|}{$12 \mathrm{M}$} & \multicolumn{2}{|c|}{$24 \mathrm{M}$} \\
\hline & & Coef. & $\mathrm{p}$-value & Coef. & p-value & Coef. & p-value & Coef. & $\mathrm{p}$-value & Coef. & p-value & Coef. & $\mathrm{p}$-value \\
\hline BTM (H-L) & + & 0.86 & 0.12 & 1.11 & 0.08 & 1.08 & 0.08 & -0.54 & 0.84 & -0.29 & 0.73 & 0.00 & 0.51 \\
\hline BTM (M-L) & + & 1.16 & 0.01 & 1.25 & 0.01 & 1.02 & 0.02 & -0.43 & 0.90 & -0.31 & 0.82 & -0.16 & 0.69 \\
\hline BTM (H-M) & - & -0.24 & 0.36 & -0.13 & 0.44 & 0.08 & 0.67 & -0.09 & 0.36 & 0.03 & 0.51 & 0.14 & 0.70 \\
\hline SIZ (S-B) & - & -0.34 & 0.26 & -0.11 & 0.51 & 0.03 & 0.60 & -0.05 & 0.45 & 0.15 & 0.62 & 0.24 & 0.70 \\
\hline VOL (H-L) & - & -1.73 & 0.03 & -1.81 & 0.03 & -1.45 & 0.02 & -0.74 & 0.13 & -0.69 & 0.14 & -0.67 & 0.13 \\
\hline DIV (H-L) & + & 1.06 & 0.04 & 1.16 & 0.01 & 1.07 & 0.02 & 0.31 & 0.21 & 0.33 & 0.18 & 0.24 & 0.24 \\
\hline GERMANY & ES & Coef. & $\mathrm{p}$-value & Coef. & p-value & Coef. & $\mathrm{p}$-value & Coef. & $\mathrm{p}$-value & Coef. & $\mathrm{p}$-value & Coef. & $\mathrm{p}$-value \\
\hline BTM (H-L) & + & 2.09 & 0.04 & 2.39 & 0.04 & 2.19 & 0.03 & 0.66 & 0.13 & 0.78 & 0.11 & 0.78 & 0.07 \\
\hline BTM (M-L) & + & 0.53 & 0.16 & 0.51 & 0.18 & 0.34 & 0.27 & 0.08 & 0.40 & 0.14 & 0.34 & 0.13 & 0.34 \\
\hline BTM (H-M) & - & 1.51 & 0.96 & 1.86 & 0.98 & 1.87 & 0.99 & 0.58 & 0.92 & 0.60 & 0.93 & 0.66 & 0.98 \\
\hline SIZ (S-B) & - & 0.85 & 0.85 & 1.04 & 0.85 & 0.45 & 0.75 & 0.83 & 0.96 & 0.80 & 0.96 & 0.78 & 0.97 \\
\hline VOL (H-L) & - & -2.53 & 0.03 & -2.71 & 0.02 & -2.71 & 0.01 & -0.64 & 0.20 & -0.85 & 0.12 & -0.71 & 0.16 \\
\hline DIV (H-L) & + & 2.42 & 0.02 & 2.54 & 0.01 & 2.06 & 0.03 & 0.08 & 0.46 & 0.11 & 0.41 & 0.04 & 0.49 \\
\hline SPAIN & ES & Coef. & $\mathrm{p}$-value & Coef. & $\mathrm{p}$-value & Coef. & $\mathrm{p}$-value & Coef. & p-value & Coef. & $p$-value & Coef. & $p$-value \\
\hline BTM (H-L) & + & -0.25 & 0.36 & 0.06 & 0.39 & 0.14 & 0.33 & 0.38 & 0.16 & 0.47 & 0.07 & 0.44 & 0.09 \\
\hline BTM (M-L) & + & -0.07 & 0.47 & 0.00 & 0.57 & 0.12 & 0.35 & -0.24 & 0.73 & -0.11 & 0.62 & 0.01 & 0.49 \\
\hline BTM (H-M) & - & -0.15 & 0.36 & 0.05 & 0.57 & 0.03 & 0.52 & 0.63 & 0.98 & 0.56 & 0.96 & 0.41 & 0.93 \\
\hline SIZ (S-B) & - & -0.40 & 0.16 & -0.25 & 0.24 & -0.26 & 0.22 & 0.35 & 0.84 & 0.39 & 0.87 & 0.32 & 0.87 \\
\hline VOL (H-L) & - & -0.26 & 0.30 & -0.39 & 0.22 & -0.40 & 0.21 & 0.88 & 0.93 & 0.74 & 0.90 & 0.60 & 0.89 \\
\hline DIV (H-L) & + & 1.50 & 0.02 & 1.32 & 0.04 & 0.89 & 0.12 & -0.24 & 0.37 & -0.24 & 0.35 & -0.35 & 0.26 \\
\hline UK & ES & Coef. & $\mathrm{p}$-value & Coef. & $\mathrm{p}$-value & Coef. & $\mathrm{p}$-value & Coef. & $\mathrm{p}$-value & Coef. & $\mathrm{p}$-value & Coef. & $\mathrm{p}$-value \\
\hline BTM (H-L) & + & 1.21 & 0.04 & 1.43 & 0.03 & 1.32 & 0.02 & 0.16 & 0.38 & 0.24 & 0.29 & 0.20 & 0.28 \\
\hline BTM (M-L) & + & 0.82 & 0.09 & 0.97 & 0.09 & 0.97 & 0.05 & 0.17 & 0.34 & 0.28 & 0.22 & 0.27 & 0.19 \\
\hline BTM (H-M) & - & 0.37 & 0.95 & 0.42 & 0.96 & 0.32 & 0.91 & 0.00 & 0.49 & -0.02 & 0.45 & -0.06 & 0.35 \\
\hline SIZ (S-B) & - & -0.94 & 0.03 & -0.58 & 0.09 & -0.42 & 0.16 & -0.48 & 0.06 & -0.32 & 0.13 & -0.22 & 0.23 \\
\hline VOL (H-L) & - & -1.78 & 0.00 & -1.81 & 0.01 & -1.54 & 0.00 & -0.61 & 0.08 & -0.66 & 0.06 & -0.60 & 0.05 \\
\hline DIV (H-L) & + & 1.46 & 0.01 & 1.54 & 0.01 & 1.45 & 0.03 & 0.37 & 0.19 & 0.41 & 0.15 & 0.20 & 0.28 \\
\hline
\end{tabular}

Regressions of long-short portfolios constructed following the approach used by Jegadeesh and Titman (2001) for horizons of 6,12 and 24 months. Portfolios were constructed for Book-to-market ratio (BTM), size (SIZ), volatility (VOL) and dividend (DIV). The high (H)/big (B) portfolio was formed from the top $20 \%$ of the stocks and the low (L)/small (S) portfolio from those in the first quintile. The medium (M) portfolio was formed from the stocks in the third quintile. The sentiment indicators are Baker and Wurgler's (2006), BW index, constructed from the first principal component of 6 proxies, for the period 1990 to 2007 and the European investor sentiment index EU SENT, constructed from the first principal component of the first factors obtained for Spain, the UK, Germany and France for the period 1992 to 2007 . These first factors explain the common variance of the three sentiment indicators/indices. We use a block bootstrap method to compute the simulated p-value for the null hypothesis that the coefficient has the expected sign. The macroeconomic variables included are the industrial output index, durable goods consumption, consumer goods consumption and the unemployment index. As independent variables, the analysis also includes the market risk premium (RMRF) and the Fama-French risk factors (HML and SMB) for each of the four European markets included in the system of equation. 
Table 8: Regressions for the four countries jointly.

Panel A: Global Portfolios.

\begin{tabular}{rrrrrrr}
\hline & & \multicolumn{3}{c}{ BW } & \multicolumn{2}{c}{ SENT EU } \\
\cline { 3 - 7 } & & \multicolumn{3}{c}{$12 \mathrm{M}$} & \multicolumn{2}{c}{$12 \mathrm{M}$} \\
\hline BTM (H-L) & + & 2.09 & 0.05 & 0.45 & p-value \\
\hline BTM (M-L) & + & 1.58 & 0.05 & 0.26 & 0.14 \\
BTM (H-M) & - & 0.50 & 0.92 & 0.20 & 0.22 \\
SIZ (S-B) & - & 0.10 & 0.62 & 0.00 & 0.93 \\
VOL (H-L) & - & -3.54 & 0.01 & -0.75 & 0.51 \\
DIV (H-L) & + & 2.22 & 0.04 & 0.60 & 0.09 \\
\hline
\end{tabular}

Panel B: Portfolios constructed with the same number of stocks for every country.

\begin{tabular}{rrrrrrr}
\hline & & \multicolumn{3}{c}{ BW } & \multicolumn{2}{c}{ SENT EU } \\
\cline { 3 - 7 } & & \multicolumn{3}{c}{$12 \mathrm{M}$} & \multicolumn{2}{c}{$12 \mathrm{M}$} \\
\hline ES & Coef. & p-value & Coef. & p-value \\
\hline BTM (H-L) & + & 1.67 & 0.07 & 0.43 & 0.14 \\
BTM (H-L) & + & 1.16 & 0.07 & 0.20 & 0.29 \\
SIZ (S-B) & - & 0.52 & 0.93 & 0.24 & 0.96 \\
VOL (H-L) & - & 0.06 & 0.61 & 0.13 & 0.72 \\
DIV (H-L) & + & -2.93 & 0.01 & -0.55 & 0.14 \\
\hline
\end{tabular}

Panel C: Portfolios constructed with the number of stocks for each country proportional to its share in total securities.

\begin{tabular}{rrrrrrr}
\hline & & \multicolumn{3}{c}{ BW } & \multicolumn{2}{c}{ SENT EU } \\
\cline { 3 - 7 } & & & \multicolumn{2}{c}{$12 \mathrm{M}$} & \multicolumn{2}{c}{$12 \mathrm{M}$} \\
\hline BTM (H-L) & + & 2.01 & 0.08 & 0.37 & p-value \\
\hline BTM (M-L) & + & 1.27 & 0.10 & 0.20 & 0.24 \\
BTM (H-M) & - & 0.63 & 0.93 & 0.20 & 0.31 \\
SIZ (S-B) & - & -0.04 & 0.50 & 0.20 & 0.85 \\
VOL (H-L) & - & -3.31 & 0.02 & -0.70 & 0.87 \\
DIV (H-L) & + & 2.45 & 0.03 & 0.55 & 0.15 \\
\hline
\end{tabular}

Regression of the stock characteristic portfolios for the four countries jointly, using the orthogonalized sentiment index as the independent variable. P-values are computed by means of a block-bootstrap procedure. The asset characteristics considered are the book-to-market ratio (BTM), size (SIZ), volatility (VOL) and dividends (DIV). The portfolios were constructed as in Jegadeesh and Titman (2001) grouping all the stocks of Spain, the UK, Germany and France for a time horizon of 6, 12 and 24 months. For the sake of brevity, only the 12-month returns are shown. The results shown in Panel A are for the portfolios of the 4 countries constructed with no limit on the number of stocks from each country. The results in Panel B are for the portfolios constructed with the same number of stocks for every country and the results in Panel C are for the portfolios constructed with the number of stocks for each country proportional to its share in total securities. The periods of analysis run from 1990 to 2007 for the orthogonal BW index and from 1992 to a 2007 for the orthogonalized SENT EU index. 
Table 9: Results of the multilevel regression

\begin{tabular}{rccccc}
\hline & & \multicolumn{3}{c}{ BW } & \multicolumn{2}{c}{ SENT EU } \\
\cline { 3 - 6 } & & \multicolumn{2}{c}{$12 \mathrm{M}$} & \multicolumn{2}{c}{$12 \mathrm{M}$} \\
\hline & ES & Coef. & p-value & Coef. & p-value \\
\hline BTM (H-L) & + & 1.95 & 0.04 & 0.45 & 0.07 \\
BTM (M-L) & + & 1.35 & 0.02 & 0.20 & 0.07 \\
BTM (H-M) & - & 0.59 & 0.20 & 0.25 & 0.23 \\
SIZ (S-B) & - & 0.13 & 0.35 & 0.15 & 0.57 \\
VOL (H-L) & - & -3.12 & 0.04 & -0.52 & 0.13 \\
DIV (H-L) & + & 2.37 & 0.05 & 0.30 & 0.26 \\
\hline
\end{tabular}

Regression of the stock characteristic portfolios for the four countries jointly, using the orthogonalized sentiment index as the independent variable. The asset characteristics considered are the book-tomarket ratio (BTM), size (SIZ), volatility (VOL) and dividends (DIV). The portfolios were constructed as in Jegadeesh and Titman (2001) grouping all the stocks of Spain, the UK, Germany and France for a time horizon of 6,12 and 24 months. For the sake of brevity, only the 12-month returns are shown. The periods of analysis run from 1990 to 2007 for the orthogonal BW index and from 1992 to a 2007 for the orthogonalized SENT EU index. 
Table 10: Coefficients of variation in stock characteristics by country for the period 1990-2007.

Panel A: Coefficients of variation

\begin{tabular}{rcccc} 
Coef. Variation & FR & GE & SP & UK \\
\hline BTM & 1.80 & 3.25 & 1.26 & 1.45 \\
SIZ & 5.09 & 5.11 & 3.16 & 6.27 \\
VOL & 0.95 & 0.79 & 0.68 & 0.72 \\
DIV & 4.99 & 3.76 & 3.20 & 2.84 \\
\hline
\end{tabular}

Panel B: Results of the difference in means tests between the coefficients of variation

\begin{tabular}{|c|c|c|c|c|c|c|c|c|c|}
\hline \multicolumn{5}{|l|}{ BTM } & \multicolumn{5}{|l|}{ VOL } \\
\hline $\mathrm{p}$-value & FR & GE & $\mathrm{SP}$ & UK & $\mathrm{p}$-value & FR & GE & $\mathrm{SP}$ & UK \\
\hline FR & 1.00 & & & & FR & 1.00 & & & \\
\hline GE & 0.00 & 1.00 & & & GE & 0.00 & 1.00 & & \\
\hline SP & 0.00 & 0.00 & 1.00 & & SP & 0.00 & 0.28 & 1.00 & \\
\hline UK & 0.00 & 0.00 & 0.00 & 1.00 & UK & 0.00 & 0.02 & 0.00 & 1.00 \\
\hline \multicolumn{2}{|l|}{ SIZ } & & & & \multicolumn{2}{|l|}{ DIV } & & & \\
\hline p-value & FR & GE & $\mathrm{SP}$ & UK & $\mathrm{p}$-value & FR & GE & $\mathrm{SP}$ & UK \\
\hline FR & 1.00 & & & & FR & 1.00 & & & \\
\hline GE & 0.83 & 1.00 & & & GE & 0.00 & 1.00 & & \\
\hline SP & 0.00 & 0.00 & 1.00 & & SP & 0.00 & 0.00 & 1.00 & \\
\hline UK & 0.00 & 0.00 & 0.00 & 1.00 & UK & 0.00 & 0.00 & 0.00 & 1.00 \\
\hline
\end{tabular}

Panel A shows the time-series average coefficients of variation for the various

characteristics considered: book-to-market ratio (BTM), size (SIZ), volatility (VOL) and dividends (DIV), for each of the markets analyzed. Panel B shows the results of the

difference in means tests between the coefficients, along with their levels of significance. FR: France, GE: Germany, SP: Spain, UK: the UK. 
Table 11: Results of the tests of cross-country differences in the coefficients of the impact of investor sentiment on the various portfolio returns.

\begin{tabular}{|c|c|c|c|c|c|}
\hline \multirow{3}{*}{ BTM (H-L) } & \multirow{3}{*}{ ES } & \multicolumn{2}{|c|}{$\mathrm{BW}$} & \multicolumn{2}{|c|}{ SENT EU } \\
\hline & & \multicolumn{2}{|c|}{$12 \mathrm{M}$} & \multicolumn{2}{|c|}{$12 \mathrm{M}$} \\
\hline & & Coef. & $\mathrm{p}$-value & Coef. & $\mathrm{p}$-value \\
\hline GE-FR & + & 0.45 & 0.37 & 1.14 & 0.16 \\
\hline GE-UK & + & -0.16 & 0.51 & 0.08 & 0.52 \\
\hline GE-SP & + & 1.31 & 0.16 & -1.38 & 0.60 \\
\hline FR-UK & + & -0.61 & 0.66 & -1.06 & 0.90 \\
\hline FR-SP & + & 1.31 & 0.10 & -1.38 & 0.98 \\
\hline UK-SP & + & 1.91 & 0.05 & -0.32 & 0.68 \\
\hline \multirow[t]{2}{*}{ SIZ (S-B) } & & \multicolumn{2}{|c|}{$12 \mathrm{M}$} & \multicolumn{2}{|c|}{$12 \mathrm{M}$} \\
\hline & & Coef. & p-value & Coef. & $\mathrm{p}$-value \\
\hline UK-FR & - & -2.11 & 0.02 & -1.25 & 0.08 \\
\hline UK-GE & - & -1.50 & 0.09 & -1.10 & 0.08 \\
\hline UK-SP & - & -1.72 & 0.03 & -1.33 & 0.04 \\
\hline GE-FR & - & -0.62 & 0.27 & -0.15 & 0.43 \\
\hline GE-SP & - & -0.23 & 0.43 & -0.23 & 0.39 \\
\hline FR-SP & - & 0.39 & 0.69 & -0.08 & 0.47 \\
\hline \multirow[t]{2}{*}{ VOL (H-L) } & & \multicolumn{2}{|c|}{$12 \mathrm{M}$} & \multicolumn{2}{|c|}{$12 \mathrm{M}$} \\
\hline & & Coef. & p-value & Coef. & $\mathrm{p}$-value \\
\hline FR-GE & - & 2.10 & 0.86 & 0.78 & 0.72 \\
\hline FR-UK & - & 2.02 & 0.91 & 1.04 & 0.79 \\
\hline FR-SP & - & -0.93 & 0.21 & -0.48 & 0.33 \\
\hline GE-UK & - & -0.08 & 0.47 & 0.26 & 0.59 \\
\hline GE-SP & - & -0.93 & 0.05 & -0.48 & 0.12 \\
\hline UK-SP & - & -2.95 & 0.01 & -1.52 & 0.08 \\
\hline \multirow[t]{2}{*}{ DIV (H-L) } & & \multicolumn{2}{|c|}{$12 \mathrm{M}$} & \multicolumn{2}{|c|}{$12 \mathrm{M}$} \\
\hline & & Coef. & $\mathrm{p}$-value & Coef. & $\mathrm{p}$-value \\
\hline FR-GE & + & -2.12 & 0.94 & -0.42 & 0.66 \\
\hline FR-UK & + & -1.65 & 0.93 & -0.83 & 0.69 \\
\hline FR-SP & + & -0.04 & 0.53 & -0.05 & 0.52 \\
\hline GE-UK & + & 0.47 & 0.34 & -0.41 & 0.67 \\
\hline GE-SP & + & 2.08 & 0.06 & 0.37 & 0.35 \\
\hline UK-SP & + & 1.61 & 0.07 & 0.78 & 0.19 \\
\hline
\end{tabular}

Results of the tests of differences between countries with respect to their estimated coefficients of investor sentiment for the 12-month stock characteristic portfolios (book-to-market ratio (BTM), size (SIZ), volatility (VOL) and dividends (DIV)). The time-series bootstrap coefficient estimates from model 6 are resampled 10,000 times to compute the simulated $p$-value for the null hypothesis that $\mathrm{Ho}: \mathrm{A}-\mathrm{B}>0$ if expected sign (ES) is positive and Ho:A-B<0 if it is negative (A,B = FR, GE, SP and UK). 
Table 12: Results of the multilevel regression

\begin{tabular}{cccccc}
\hline & & \multicolumn{2}{c}{ II } & \multicolumn{2}{c}{ SENTIX } \\
\cline { 3 - 6 } & & & 12M & 12M \\
\hline & ES & Coef. & p-value & Coef. & p-value \\
\hline BTM (H-L) & + & 2.58 & 0.00 & 2.00 & 0.10 \\
BTM (M-L) & + & 3.01 & 0.01 & 1.48 & 0.06 \\
BTM (H-M) & - & -0.43 & 0.46 & 0.53 & 0.56 \\
SIZ (S-B) & - & 3.49 & 0.17 & 4.80 & 0.18 \\
VOL (H-L) & - & -1.55 & 0.00 & -1.39 & 0.04 \\
DIV (H-L) & + & 1.76 & 0.21 & -0.57 & 0.58 \\
\hline
\end{tabular}

Regression of the stock characteristic portfolios for the four countries jointly, using the direct sentiment index (II for US market and Sentix Eurostoxx 50 for euroland) as the independent variable.. The asset characteristics considered are the book-to-market ratio (BTM), size (SIZ), volatility (VOL) and dividends (DIV). The portfolios were constructed as in Jegadeesh and Titman (2001) grouping all the stocks of Spain, the UK, Germany and France for a time horizon of 12 months. The periods of analysis run from 1990 to 2007 for the II index and from 2001 to a 2007 for the Sentix index. 
Table 13: Results of the tests of cross-country differences in the coefficients of the impact of investor sentiment on the various portfolio returns.

\begin{tabular}{|c|c|c|c|c|c|}
\hline & & \multicolumn{2}{|c|}{ II } & \multicolumn{2}{|c|}{ SENTIX } \\
\hline BTM (H-L) & ES & \multicolumn{2}{|c|}{$12 \mathrm{M}$} & \multicolumn{2}{|c|}{$12 \mathrm{M}$} \\
\hline & & Coef. & $\mathrm{p}$-value & Coef. & $\mathrm{p}$-value \\
\hline GE-FR & + & -0.01 & 0.89 & 0.03 & 0.38 \\
\hline GE-UK & + & 0.00 & 0.98 & 0.04 & 0.24 \\
\hline GE-SP & + & 0.00 & 0.91 & 0.04 & 0.23 \\
\hline FR-UK & + & 0.00 & 0.89 & 0.01 & 0.76 \\
\hline FR-SP & + & 0.01 & 0.75 & 0.01 & 0.74 \\
\hline UK-SP & + & 0.01 & 0.84 & 0.00 & 0.97 \\
\hline \multirow[t]{2}{*}{ SIZ (S-B) } & & \multicolumn{2}{|c|}{$12 \mathrm{M}$} & \multicolumn{2}{|c|}{$12 \mathrm{M}$} \\
\hline & & Coef. & $\mathrm{p}$-value & Coef. & $p$-value \\
\hline UK-FR & - & -0.02 & 0.53 & -0.03 & 0.31 \\
\hline UK-GE & - & -0.01 & 0.83 & -0.03 & 0.53 \\
\hline UK-SP & - & 0.00 & 0.95 & 0.01 & 0.80 \\
\hline GE-FR & - & -0.01 & 0.75 & 0.00 & 0.92 \\
\hline GE-SP & - & 0.01 & 0.89 & 0.04 & 0.42 \\
\hline FR-SP & - & 0.02 & 0.64 & 0.04 & 0.21 \\
\hline \multirow[t]{2}{*}{ VOL (H-L) } & & \multicolumn{2}{|c|}{$12 \mathrm{M}$} & \multicolumn{2}{|c|}{$12 \mathrm{M}$} \\
\hline & & Coef. & $\mathrm{p}$-value & Coef. & $\mathrm{p}$-value \\
\hline FR-GE & - & 0.10 & 0.05 & 0.02 & 0.74 \\
\hline FR-UK & - & 0.04 & 0.35 & 0.01 & 0.83 \\
\hline FR-SP & - & 0.04 & 0.30 & 0.01 & 0.81 \\
\hline GE-UK & - & -0.06 & 0.21 & -0.01 & 0.86 \\
\hline GE-SP & - & -0.06 & 0.26 & -0.01 & 0.88 \\
\hline UK-SP & - & 0.01 & 0.88 & 0.00 & 0.98 \\
\hline \multirow[t]{2}{*}{ DIV (H-L) } & & \multicolumn{2}{|c|}{$12 \mathrm{M}$} & \multicolumn{2}{|c|}{$12 \mathrm{M}$} \\
\hline & & Coef. & $\mathrm{p}$-value & Coef. & p-value \\
\hline FR-GE & + & -0.05 & 0.21 & -0.04 & 0.31 \\
\hline FR-UK & + & 0.00 & 0.94 & -0.01 & 0.72 \\
\hline FR-SP & + & -0.03 & 0.28 & 0.00 & 0.93 \\
\hline GE-UK & + & 0.05 & 0.25 & 0.03 & 0.44 \\
\hline GE-SP & + & 0.01 & 0.74 & 0.04 & 0.32 \\
\hline UK-SP & + & -0.03 & 0.34 & 0.01 & 0.69 \\
\hline
\end{tabular}

Results of the tests of differences between countries with respect to their estimated coefficients of investor sentiment for the 12-month stock characteristic portfolios (book-to-market ratio (BTM), size (SIZ), volatility (VOL) and dividends (DIV)). We use II index or Sentix index as a proxy for investor sentiment. The time-series bootstrap coefficient estimates from model 6 are resampled 10,000 times to compute the simulated p-value for the null hypothesis that $\mathrm{Ho}: \mathrm{A}-\mathrm{B}>0$ if expected sign (ES) is positive and Ho:A-B $<0$ if it is negative ( $\mathrm{A}, \mathrm{B}=\mathrm{FR}, \mathrm{GE}, \mathrm{SP}$ and $\mathrm{UK})$. 
Table 14: Regression of the portfolio returns for the period 1996-2007.

\begin{tabular}{|c|c|c|c|c|c|c|c|}
\hline \multirow[b]{3}{*}{ FRANCE } & \multirow[b]{3}{*}{ ES } & \multicolumn{2}{|c|}{ SENT US } & \multicolumn{2}{|c|}{ SENT EU IPO } & \multicolumn{2}{|c|}{ SENT EU } \\
\hline & & \multicolumn{2}{|c|}{$12 \mathrm{M}$} & \multicolumn{2}{|c|}{$12 \mathrm{M}$} & \multicolumn{2}{|c|}{$12 \mathrm{M}$} \\
\hline & & Coef. & $\mathrm{p}$-value & Coef. & $p$-value & Coef. & $\mathrm{p}$-value \\
\hline BTM (H-L) & + & 1.03 & 0.06 & 0.66 & 0.13 & -0.12 & 0.45 \\
\hline BTM (M-L) & + & 0.58 & 0.09 & 0.40 & 0.18 & -0.29 & 0.82 \\
\hline BTM (H-M) & - & 0.44 & 0.95 & 0.26 & 0.81 & 0.19 & 0.69 \\
\hline SIZ (S-B) & - & 0.91 & 0.98 & 0.10 & 0.64 & -0.31 & 0.27 \\
\hline VOL (H-L) & - & -0.15 & 0.37 & -1.57 & 0.02 & -0.21 & 0.39 \\
\hline DIV (H-L) & + & 0.25 & 0.25 & 1.13 & 0.01 & -0.15 & 0.55 \\
\hline GERMANY & $\mathrm{ES}$ & Coef. & $\mathrm{p}$-value & Coef. & $\mathrm{p}$-value & Coef. & $\mathrm{p}$-value \\
\hline BTM (H-L) & + & 1.26 & 0.09 & 1.14 & 0.08 & 0.86 & 0.25 \\
\hline BTM (M-L) & + & 0.31 & 0.22 & 0.29 & 0.28 & 0.29 & 0.31 \\
\hline BTM (H-M) & - & 0.96 & 0.96 & 0.81 & 0.94 & 0.56 & 0.77 \\
\hline SIZ (S-B) & - & 0.39 & 0.61 & 0.69 & 0.86 & 1.21 & 0.89 \\
\hline VOL (H-L) & - & -1.32 & 0.09 & -0.72 & 0.25 & -0.79 & 0.25 \\
\hline DIV (H-L) & + & 1.10 & 0.07 & 0.35 & 0.36 & 0.29 & 0.38 \\
\hline SPAIN & ES & Coef. & $\mathrm{p}$-value & Coef. & $p$-value & Coef. & $\mathrm{p}$-value \\
\hline BTM (H-L) & + & 0.50 & 0.07 & 0.74 & 0.01 & 0.56 & 0.09 \\
\hline BTM (M-L) & + & 0.13 & 0.30 & 0.56 & 0.06 & 0.20 & 0.31 \\
\hline BTM (H-M) & - & 0.41 & 0.97 & 0.17 & 0.73 & 0.40 & 0.87 \\
\hline SIZ (S-B) & - & 0.82 & 0.97 & -0.19 & 0.36 & 0.23 & 0.64 \\
\hline VOL (H-L) & - & -0.02 & 0.42 & -1.12 & 0.04 & -0.59 & 0.21 \\
\hline DIV (H-L) & + & 0.46 & 0.19 & 0.86 & 0.12 & 0.61 & 0.21 \\
\hline UK & ES & Coef. & $\mathrm{p}$-value & Coef. & $p$-value & Coef. & $p$-value \\
\hline BTM (H-L) & + & 1.05 & 0.08 & 0.73 & 0.09 & 0.82 & 0.10 \\
\hline BTM (M-L) & + & 0.90 & 0.08 & 0.77 & 0.03 & 0.77 & 0.05 \\
\hline BTM (H-M) & - & 0.11 & 0.71 & -0.04 & 0.40 & 0.04 & 0.58 \\
\hline SIZ (S-B) & - & -0.67 & 0.09 & -0.93 & 0.01 & -0.48 & 0.17 \\
\hline VOL (H-L) & - & -1.79 & 0.03 & -1.66 & 0.01 & -1.81 & 0.03 \\
\hline DIV (H-L) & + & 1.46 & 0.02 & 1.45 & 0.01 & 1.18 & 0.05 \\
\hline
\end{tabular}

Regressions of long-short portfolios constructed following the approach used by Jegadeesh and Titman (2001) for a 6, 12 and 24 month time horizon. Portfolios were formed based on stock characteristics: book-to-market ratio (BTM), size (SIZ), volatility (VOL) and dividend (DIV). The high (H)/big (B) portfolio was formed from the top $20 \%$ of the stocks and the low (L)/small (S) portfolio from those in the first quintile. The medium (M) portfolio from the stocks in the third quintile. The sentiment indicators considered are the US SENT index, the SENT EU index (the table shows the results of the latter for the period 1996-2007 to enable comparison with the SENT EU IPO index) and the SENT EU IPO index. The SENT US index was constructed from the first principal component of 3 proxies, which are the same as those used to form the SENT EU index, except for the volatility premium, which is replaced by the dividend premium. The SENT EU IPO index was formed from the first principal component of the first factor extracted for each of the three markets. These first factors explain the common variance between the five sentiment indicators for Spain and four for the UK. In the case of Germany and France, three indicators are included in the construction of the SENT EU index. We use a block bootstrap method to compute the simulated p-value for the null hypothesis that the coefficient has the expected sign. The macroeconomic variables considered are the industrial output index, durable goods consumption, consumer goods consumption and the unemployment index. 